\title{
Competition in the quality of higher education: the impact of student mobility
}

\author{
Gabrielle Demange $^{1} \cdot$ Robert Fenge $^{2} \cdot$ Silke Uebelmesser $^{3}$
}

Published online: 19 March 2020

(c) The Author(s) 2020

\begin{abstract}
In the last years, there has been a shift toward more private financing of higher education in many countries. At the same time, student mobility has substantially increased. This paper analyzes in a two-region model the impact of student mobility on region-specific higher education quality with private funding. Individuals decide whether and where to study based on their individual ability and the implemented quality. We show that mobility of students affects educational quality in very different ways depending on the probability of return migration. With full return migration, quality is optimally provided which is in stark contrast to the underprovision result in the case of tax financing. On the contrary, low return migration and thus more competition for students countervail the efficient provision of quality and result in too little differentiated levels or too high symmetric levels. This is in line with the overprovision result with tax financing.
\end{abstract}

Keywords Higher education · Migration · Educational quality · Vertical differentiation $\cdot$ Welfare criterion

JEL Classification $\mathrm{H} 75 \cdot \mathrm{I} 28 \cdot \mathrm{R} 23$

An earlier version of the paper has been circulated as Demange and Fenge (2009): "Vertical differentiation in the quality of higher education when students are mobile." The present paper is a largely revised and extended version.

Silke Uebelmesser

silke.uebelmesser@uni-jena.de

1 Paris School of Economics-EHESS, Paris, France

2 University of Rostock and CESifo, Rostock, Germany

3 Friedrich-Schiller-University Jena and CESifo, Jena, Germany 


\section{Introduction}

During the last few decades, student mobility has substantially increased (OECD 2019). At the same time, more and more mobile students stay on after graduation. Even though the extent of return migration varies considerably across countries and depends on several factors (see, e.g., Lu et al. 2009; Tremblay 2005), there is empirical evidence showing that the fraction of foreign students who stay in their host country upon graduation is substantial (see, e.g., Rosenzweig 2006; Lowell et al. 2007; Van Bouwel and Veugelers 2014). Hence, there seems to be scope for competition for students (and graduates) and many OECD countries are aware of this (Chaloff and Lemaitre 2009). One possible approach is to try to affect the return migration rates. Lowell et al. (2007) report that, for example, the visa application process is a strong policy tool to attract and to keep foreign students. Another option is to aim at directly attracting students. Competition may take many forms and depend critically on various factors such as the probability of return migration after students have graduated and the financing system.

In a tax-financed system, the return probability of graduates critically affects the provision of higher education. Governments underinvest in public education, because of the free-rider problem, as long as some of their native students come back (see, e.g., Del Rey 2001; Mechtenberg and Strausz 2008) or because they ignore the positive externalities due to the emigration of some of their graduates (Justman and Thisse 2000). ${ }^{1}$ Delpierre and Verheyden (2014) consider a setting with student and worker mobility under university and government competition. In equilibrium, government competition dominates and the free-rider effect results in underinvestment in human capital. Overall, the consequences of the free-rider effect for the provision of higher education, following from tax financing and the mobility of students and graduates, have been widely studied. ${ }^{2}$

In the last years, however, there has been a shift toward a larger share of private financing of higher education. The UK is a case in point, but this pattern can be more broadly observed as a reaction to tighter public budgets or to the increase in student mobility (see, e.g., Haussen and Uebelmesser 2016). In this paper, we go one step further and assume that higher education is fully fee-financed. ${ }^{3}$ As students bear the additional cost of education, their choice whether to study and where is determined by the return of the investment, i.e., the quality of education. As a result, governments compete in educational quality. ${ }^{4}$

\footnotetext{
1 Lange (2009) extends the analysis by allowing for mobility of both skilled workers and students. Depending on the stay rate of graduates, over- or underinvestment in education is possible.

2 For example, in Demange et al. (2014), we study the impact of the mobility of skilled workers and students when credit markets are imperfect and equilibrium wages are endogenous due to nonlinear production function.

3 The implicit assumption is that there is a fee-financed part of higher education (quality), beside possibly a tax-financed basic part.

4 Indeed, the introduction or extension of tuition fees in many regions and countries has provided an additional source of funding to improve educational quality. See also Kemnitz (2007) who shows this in a decentralized system of higher education.
} 
The aim of the paper is to inquire to what extent the competition outcome, i.e., the resulting differentiation in educational quality, is efficient with fee financing. We focus on competition between similar regions so that any differentiation in educational quality stems from pure strategic effects. To assess the relevance, efficiency, and stability of different strategies, we analyze the Nash equilibria of the model and their welfare properties. As individuals benefit differently from higher education based on their innate ability, the choice of an educational quality level may be used as a way to attract or to repel individuals according to their ability. To examine the incentives to do so, we build a simple model in which the decisions of both students and regions are derived through well-specified welfare criteria. ${ }^{5}$ There is an optimal level of vertical differentiation in educational quality which enables individuals to split according to their abilities. ${ }^{6}$ Whether governments indeed choose the optimal differentiation depends on the graduates' return probability and the government's objective.

A central insight of our model is that more competition for students countervails the efficient differentiation of quality levels. This is the case although only the mobility of students establishes the option of efficient differentiation between regions in the first place. The reason for the welfare loss is that competition for students generates external effects of migration which lead to suboptimal differentiation. The return probability of foreign students determines the strength of the motivation of governments to compete for students. In the extreme case where all foreign students return back home after graduation, there is no benefit of competing for students from other regions. Hence, there is no distortion due to mobility and governments differentiate their quality levels optimally at a Nash equilibrium. However, the smaller the return migration, the stronger is the educational competition and the more quality levels converge across regions yielding a lower-than-efficient differentiation. In the other extreme of no return migration, differentiation vanishes completely. The resulting identical quality level is too high compared with the optimal one in a single closed economy. Hence, with open borders, students' mobility may induce regions to over-provide the quality of higher education as long as the return migration is negligible while at the same time choosing suboptimal quality differentiation.

Similarly to the analyses that focus on a tax-financed system, it turns out that graduates' return migration plays an important role in a fee-financed system. There are, however, important differences when it comes to the optimality of the outcomes. With full return migration, there are no incentives to compete for students in both systems. In the case of tax-financed higher education, the strong free-riding

\footnotetext{
5 Our model has some similarities with models of vertical product differentiation as developed by Gabszewicz and Thisse (1979) and Shaked and Sutton (1982). However, the profit maximizing firms are replaced by regions whose objective is citizens' welfare.

6 We do not consider selection of students based on their ability. Abilities have to be observable via tests, certificates, etc., which is not easily given in an international context due to the (still) limited comparability of qualifications. Apart from that, it is important to realize that the very good students can only be selected, if the pool of candidates is very good. One possible instrument to improve the quality of the pool is to offer high-quality higher education. With our stylized model, we study the relation between the educational quality level of higher education and the quality of the candidates.
} 
incentive with full return migration dominates and leads to underprovision. This is in stark contrast to the result of no distortion with fee financing which follows from the incentives for differentiation in order to realize the efficiency gains.

On the contrary, with a low return probability of graduates, there are incentives to compete for students both in the tax-financed system and in the fee-financed system. With fee financing, regions provide a too high and too little differentiated quality level in an attempt to attract highly able students. This is in line with the overprovision result with tax financing following a similar logic of competition. For intermediate values of the return probability, the equilibria result from the two forces at work: incentives for differentiation called by efficiency gains and incentives to compete for students. However, even in the situation in which there is an asymmetric equilibrium with differentiated educational quality levels, governments tend to choose suboptimally differentiated levels. The distortions due to the competition for skilled workers via mobile students thus dominate.

There are two recent papers that are closest to our analysis. Kemnitz (2007) compares the impact of different funding schemes and different degrees of university autonomy on competition between universities. He considers a closed-economy model with vertical differentiation in which tuition fees and educational quality are endogenously determined. Haupt et al. (2016) consider similar policy instruments in an open-economy setting with two developed regions which compete for students from the developing world. They show that in equilibrium educational qualities are differentiated in order to relax tuition fee competition. Furthermore, they find that the region with the higher educational quality level decreases this level with a lower return probability of foreign students. ${ }^{7}$

Our paper extends this analysis. We focus on the impact of students' mobility on the competition via educational qualities and assume private funding. In our model, the decisions of students both whether and where to study are endogenous. Combined with exogenous return probabilities of foreign students, this allows us to analyze equilibria with differentiated educational qualities as well as with symmetric ones. Furthermore, we find unambiguous welfare implications: In an asymmetric equilibrium, the differentiation of educational quality levels is inefficiently low, while in a symmetric equilibrium, the educational quality level is too high.

The outline of the paper is as follows. Section 2 describes the model. In Sect. 3, we analyze a closed economy. Section 4 considers an open-economy setting. We first derive the optimal allocation, i.e., the cooperative benchmark, and then introduce the noncooperative setting and the scope for differentiation. In Sect. 5, we determine the symmetric or asymmetric Nash equilibria of the model for different return probabilities and analyze the efficiency of the results. Section 6 concludes.

\footnotetext{
7 Lange (2013) provides a complementary analysis to our analysis with a focus on competition in the level of the fees for a given quality level of education.
} 


\section{The model}

The analysis is conducted in a simple stationary two-period overlapping generation model with two symmetric regions. ${ }^{8}$ The focus is on the strategic interactions. Each government chooses the educational quality level or quality level for short. These choices apply for a large enough period so that they are perceived as constant by the generations. Thus, given the quality levels chosen by the governments, individuals make their decisions about higher education and labor supply.

In more detail, in the first period of their life, individuals decide about acquiring higher education which affects labor supply in the second period. In particular, individuals decide whether and where to study. For this, they compare the lifetime income with higher education to the lifetime income when uneducated. If individuals choose not to study, they work and receive the wage income of an unskilled worker in both periods in their home region. If individuals decide to acquire higher education at home or abroad, they have to pay the tuition fees and receive no wage income in the first period. The quality level of education as well as the innate individual ability generates the skill units an individual is endowed with, which, in turn, determines his wage as a worker. Then, since the wages per skill unit are identical across regions, graduate students have no monetary incentives to choose either region to work in. In the second period of their life, they stay in the region where they have graduated or come back to their home region with some (exogenous) probability. Hence, the proposed educational quality levels determine the structure of labor supply in the two regions in the subsequent period through their direct effect on productivity and their indirect effect on the skill composition of the workforce.

We assume that the population is constant and concentrate on steady-state situations. In the following, production, education, and credit market are further specified.

Production sector The economy is kept as simple as possible. There is a single consumption good which cannot be stored. There is no capital. The production sector in each region uses two kinds of input: labor supplied by individuals with and without higher education, $L_{\mathrm{s}}$ (skilled labor) and $L_{\mathrm{u}}$ (unskilled labor), respectively. Production takes place according to a linear technology. The marginal productivities are constant. We assume a competitive labor market. The wage rates of the skilled workers, $w_{\mathrm{s}}$, and of the unskilled workers, $w_{\mathrm{u}}$, are equal to the respective marginal productivities. They are given and are constant

$$
F\left(L_{\mathrm{u}}, L_{\mathrm{s}}\right)=w_{\mathrm{s}} L_{\mathrm{s}}+w_{\mathrm{u}} L_{\mathrm{u}}
$$

\footnotetext{
8 The setting in Demange et al. (2014) shows some similarities. The questions of interest and the basic assumptions are, however, very different. There, the focus is on the choice of the financial regime with imperfect credit markets within a general equilibrium model. Contrary to that, the analysis here focuses on competition in the educational quality level of higher education when higher education is feefinanced, credit markets are perfect, and wages are assumed to be given and are constant (see below).
} 
Production is thus completely determined by the labor supply of skilled and unskilled workers, which in turn is given by the individuals' decisions to acquire higher education.

Higher education Individuals are distinguished by an innate ability parameter, $y$, which reflects individually different benefits from higher education. The distribution of abilities is identical in each region and assumed to be uniform in the range $[0, \bar{y}]$. To be skilled, an individual must receive higher education. Quality of education, also called the quality level, is denoted by $e, e>0$. The level is restricted to be uniform and region-specific, meaning that it applies to all students in the region. Both the quality level of education $e$ and the individual's innate ability $y$ generate the skill units an individual is endowed with after having acquired education, which is the quantity of skilled labor provided by an educated worker: $y e$.

For simplicity, we assume that the amount of money spent for higher education per individual, given by $c(e)$, only depends on the quality level. Put differently, costs of education are proportional to the number of students for a given quality. The cost function $c$ is assumed to be increasing and strictly convex. This captures the fact that it becomes increasingly expensive to produce a further unit of educational quality. Throughout the paper, to avoid corner solutions, we shall assume that marginal costs of educational quality satisfy $c^{\prime}(0)=0$ and increase indefinitely with its level: $\lim _{e \rightarrow \infty} c^{\prime}(e)=\infty$. The costs of higher education are borne by the students via tuition fees.

The restriction to a single quality level, albeit strong, is meant to capture the observed limited variability of the quality of educational programs despite the diversity of ability types. Considering a single quality level is only a simplification, which does not alter the main insights of our results. This assumption makes it impossible for a government to achieve the first-best policy, which is to provide a specific quality level for each ability type of students. This could be justified by assuming, for example, that providing higher education leads to additional costs, which are fixed and therefore independent of the number of students. Including these costs would not affect the marginal analysis and would result in a limited number of educational quality levels. The main insights as derived below would go through: Opening the economies allows to improve welfare by offering more diverse education levels than in the closed economies. The welfare gains may not be achieved when the return probability is too low, because the optimally differentiated levels cannot be sustained at equilibrium, following the same arguments as in Sections 5.2. and 5.3. ${ }^{9}$

Credit market Credit markets are assumed to be perfect, and we are at the golden rule: The interest rate in the steady state without frictions is equal to the population growth rate, which is here equal to zero (see Gale 1973). Since students do not have any income, they have to borrow money in the first period in order to finance the tuition fees for their higher education. Borrowing takes place between the individuals of one generation (not all decide to study) and possibly between generations.

\footnotetext{
9 There is, however, a difficulty in a non-marginal analysis, in which the countries may change the number of quality levels they offer, possibly by free-riding on the other country to lower their fixed costs.
} 
As credit markets are perfectly competitive and we model higher education as a private good without externalities, pure fee financing of higher education is indeed optimal.

\section{The closed-economy setting}

We study here the individual choice of studying and the resulting labor supply given educational quality and the governmental choice of the quality in a closed economy by backward induction.

\subsection{Individual decisions and employment}

The decision whether and where to study is based on the expected lifetime income in each alternative. If an individual decides to study, in the first period, she pays the educational costs, $c(e)$, as fees and earns no wage income. In the second period, the educated worker with ability $y$ receives a gross wage rate $w_{\mathrm{s}}$ for each unit of effective labor supply so that the wage income is $w_{\mathrm{s}} y e$. Thus, her lifetime income is

$$
w_{\mathrm{s}} y e-c(e) \text {. }
$$

If the individual decides not to study she receives a wage income $w_{\mathrm{u}}$ in both periods. Hence, her lifetime income is

$$
2 w_{\mathrm{u}} \text {. }
$$

The individual compares both lifetime incomes and chooses the option which maximizes her income. The decision whether to study or not depends on the ability of the individual. The marginal ability type who is indifferent between both options is given by

$$
y^{u}=\frac{2 w_{\mathrm{u}}+c(e)}{w_{\mathrm{s}} e} .
$$

Individuals with a lower ability, $y<y^{u}$, do not study and are employed as unskilled workers in both periods. Individuals with a higher ability, $y>y^{u}$, take up higher education in the first period and work as skilled workers in the second period.

Hence, the quality levels affect the individual education choices and determine the skilled and unskilled labor supply in the subsequent period. As already mentioned, the population growth rate is assumed to be nil. In each period, employment consists of young and old unskilled workers and old skilled workers. Let a quality level $e$ and a threshold ability level of skilled workers $y^{u}$ be given. The number of unskilled workers per generation, denoted by $N_{\mathrm{u}}$, is equal to $y^{u}$ and the number of skilled workers, denoted by $N_{\mathrm{s}}$, is equal to $\bar{y}-y^{u}$ where $\bar{y}$ denotes the size of the total workforce. The employment of unskilled labor is given by 


$$
L_{\mathrm{u}}=2 \int_{0}^{y^{u}} 1 \mathrm{~d} y=2 y^{u}=2 N_{\mathrm{u}}
$$

and the effective skilled labor by

$$
\begin{aligned}
L_{\mathrm{s}} & =\int_{y^{u}}^{\bar{y}} y e \mathrm{~d} y=e\left(\frac{\bar{y}^{2}-\left(y^{u}\right)^{2}}{2}\right)=\left(\bar{y}-y^{u}\right) e\left(\frac{\bar{y}+y^{u}}{2}\right) \\
& =N_{\mathrm{s}} e\left(\frac{\bar{y}+y^{u}}{2}\right)
\end{aligned}
$$

which is equal to the number of skilled workers multiplied by their average ability and the quality level.

\subsection{Quality choice}

We now analyze the choice of the educational quality. The individual decisions as determined in the previous section are correctly expected by the government. We first derive the optimal allocation in the absence of any informational constraints. Then, we compare it to the decisions of the government when informational constraints matter.

\subsubsection{Optimal allocation}

Under complete information on individuals' abilities, a social planner can determine the level of educational quality and the minimum ability of those who study. The welfare criterion, $W$, is aggregate production net of education cost at a steady state:

$$
W(y, e)=F\left(L_{\mathrm{s}}, L_{\mathrm{u}}\right)-N_{\mathrm{s}} c(e) .
$$

This is the criterion that obtains in a fully fledged overlapping generation model economy in which the planner treats all generations equally. In other words, as assumed above, we are at the golden rule with an implicit interest rate equal to the population growth rate, here zero.

The choice of the level of educational quality and of the minimum ability of those who study, $e$ and $y$, respectively, fully determines skilled and unskilled labor from (5) and (6). Hence, we have that

$$
W(y, e)=w_{\mathrm{s}} L_{\mathrm{s}}+w_{\mathrm{u}} L_{\mathrm{u}}-N_{\mathrm{s}} c(e)
$$

where from (5) and (6) $L_{\mathrm{u}}$ and $L_{\mathrm{s}}$ are functions of $e$ and $y$ and $N_{\mathrm{s}}$ is a function of $y$ alone. The objective is to maximize $\operatorname{Max}_{y, e} W(y, e)$.

The impact of a marginal increase in $e$ keeping the set of students fixed is given by 


$$
\begin{aligned}
\frac{\partial W}{\partial e} & =w_{\mathrm{s}} \frac{\partial L_{\mathrm{s}}}{\partial e}+w_{\mathrm{u}} \frac{\partial L_{\mathrm{u}}}{\partial e}-N_{\mathrm{s}} c^{\prime}(e) \\
& =(\bar{y}-y)\left[w_{\mathrm{s}} \frac{\bar{y}+y}{2}-c^{\prime}(e)\right] .
\end{aligned}
$$

It is equal to the effect of the quality level on the production of the skilled workers minus the increase in costs.

The impact of a marginal increase in the minimum ability level $y$ keeping the quality level fixed is given by

$$
\begin{aligned}
\frac{\partial W}{\partial y} & =w_{\mathrm{s}} \frac{\partial L_{\mathrm{s}}}{\partial y}+w_{\mathrm{u}} \frac{\partial L_{\mathrm{u}}}{\partial y}-c(e) \frac{\partial N_{\mathrm{s}}}{\partial y} \\
& =-w_{\mathrm{s}} e y+2 w_{\mathrm{u}}+c(e) .
\end{aligned}
$$

It is equal to the net impact on the productivity of a student of ability just equal to $y$ from becoming skilled compared to remaining unskilled where the impact is measured at the steady-state situation.

The objective function is concave in $e$ and in $y$. At the optimum, assumed to be interior, the level of educational quality and the threshold ability level are characterized by the following first-order conditions

$$
\begin{gathered}
w_{\mathrm{s}} \frac{\bar{y}+y}{2}=c^{\prime}(e) \\
w_{\mathrm{s}} e y-2 w_{\mathrm{u}}-c(e)=0
\end{gathered}
$$

that is, the marginal gain from a change in educational quality on the average student, $w_{\mathrm{s}} \frac{\bar{y}+y}{2}$, is equal to the marginal costs, and the net gain of education for the marginal student is null.

In the sequel, we put a superscript * to indicate the values at the optimum solution for the quality levels and the threshold ability.

\subsubsection{Government's decision}

In contrast to the social planner's problem, individuals' abilities are assumed to be unobservable (or not contractible) by governments. Due to these informational asymmetries, the set of students cannot be chosen in the same way as an omniscient social planner does. The government chooses the level of educational quality taking account of the individual decisions which are determined by the threshold level of ability. The welfare criterion of the government is still the aggregate production net of education cost at a steady state.

Given a quality level, the ability threshold which determines who decides to study is denoted by $y^{u}(e)$ (Eq. (4)). Thus, the government's objective is

$$
\operatorname{Max}_{e} W\left(y^{u}(e), e\right)=w_{\mathrm{s}} L_{\mathrm{s}}+w_{\mathrm{u}} L_{\mathrm{u}}-N_{\mathrm{s}} c(e),
$$


where skilled and unskilled labor levels are those determined by the threshold ability level $y^{u}(e)$

$$
N_{\mathrm{s}}=\bar{y}-y^{u}(e), L_{\mathrm{u}}=2 y^{u}(e), L_{\mathrm{s}}=N_{\mathrm{s}} e\left(\frac{\bar{y}+y^{u}(e)}{2}\right) .
$$

The impact on welfare due to a marginal change of education is composed of two terms: an indirect one through the selection of abilities and a direct one. Formally, the marginal change in welfare that results from an increase in the quality level chosen by the government is given by

$$
\frac{\mathrm{d} W}{\mathrm{~d} e}=\frac{\partial W}{\partial y} \frac{\mathrm{d} y^{u}}{\mathrm{~d} e}+\frac{\partial W}{\partial e}
$$

where $\frac{\mathrm{d} y^{u}}{\mathrm{~d} e}$ denotes the change in the threshold ability level and thus in the selection of abilities.

The key point is that in our model individuals' choices are not distorted under full fee financing when borders are closed. In other words, the optimal ability associated with a given quality level, given by (12), coincides with that chosen by individuals, given by (4). By choosing the optimal level $e^{*}$, the associated optimal set of students is selected, those with ability larger than $y^{*}=y^{u}\left(e^{*}\right)$, and surely the government cannot do better. (More formally, both derivatives $\frac{\partial W}{\partial y}$ and $\frac{\partial W}{\partial e}$ are then null.) An immediate consequence is that the optimal allocation and the maximal value for welfare can be reached even without observing abilities.

\section{Open economy with mobile students}

We study the same model as before-now, however, with two economies. Unskilled workers are assumed to be immobile, whereas students and skilled workers are mobile across regions. ${ }^{10}$ In particular, individuals who decide to study have no migration costs and choose the region where they want to attain higher education. This assumption is in line with our aim of understanding the effects of ever higher degrees of student mobility. At the same time, (foreign) graduates are not assumed to be costlessly mobile. Graduates may stay in the region where they have completed higher education or come back to their home region with some (exogenous) return probability as described below. As mentioned in the Introduction, return probabilities vary across countries and across time. Different return probabilities capture different mobility scenarios with different mobility costs.

\footnotetext{
10 This corresponds to empirical evidence according to which mobility increases with education. See, e.g., Ehrenberg and Smith (1993), Mauro and Spilimbergo (1999), Coniglio and Prota (2008) and Hunt (2006). In our model, the results would not be affected if unskilled workers were mobile because they have no incentive to move: The unskilled wage is identical across regions due to the linear production technology (see (1)). The results would thus not be affected if unskilled workers were mobile.
} 
In our two-region setting, the focus is on the strategic interactions between the regions. As a benchmark, we start by analyzing the choice made by an omniscient social planner who can decide on the level of educational quality in each region and on the ability of those who study and at which level. An alternative interpretation of this setting is that the two regions cooperate in their choice of the levels of educational quality and have complete information on abilities. We then study a noncooperative game with incomplete information played by the two regions for various rates of return migration of the graduates who have studied abroad and we consider the possible distortions of the quality level $e$.

\subsection{Optimum (cooperative benchmark)}

We consider the aggregate welfare over the two regions as the objective. The fact that there is a uniform quality level in each region is a constraint. This opens up the possibility of overall welfare gains if quality levels differ across the two regions and students are mobile.

The omniscient social planner can choose the region-specific levels of educational quality and allocate the individuals to the higher education systems in the two regions according to their abilities. Denote by $e^{A}$ and $e^{B}$ the quality levels (even though here a quality level is not necessarily attached to a specific region). With obvious notation, overall welfare is

$$
W=w_{\mathrm{s}} L_{\mathrm{s}}+w_{\mathrm{u}} L_{\mathrm{u}}-c\left(e^{A}\right) N_{\mathrm{s}}^{A}-c\left(e^{B}\right) N_{\mathrm{s}}^{B}
$$

in which the number of students and skilled and unskilled labor are determined by the planner.

As $e$ and $y$ are complements in the determination of skilled labor, it is always optimal to assign the students with the largest ability levels to the largest quality level and not to educate the individuals whose ability levels are the lowest. If $e^{A}>e^{B}$ for instance, let $y^{A B}$ be the minimum ability of those who are assigned to a high quality level and $y^{u}$ the minimum ability of those who are allowed to study at a low quality level. Individuals with an ability between $y^{u}$ and $y^{A B}$ acquire the low level of educational quality $e^{B}$ and those with an ability between $y^{A B}$ and $\bar{y}$ acquire the high level $e^{A}$, as depicted in Fig. 1.

Hence, the policy instruments of the planner are the levels of educational quality characterized by $e^{A}$ and $e^{B}$ and the thresholds, $y^{u}$ and $y^{A B}$, which describe the abilities of those who acquire a given level of educational quality. They fully determine the number of students in each education system as well as skilled and unskilled labor

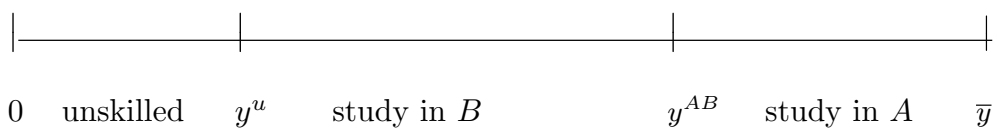

Fig. 1 Threshold levels $y^{u}$ and $y^{A B}$ for $e^{A}>e^{B}$ 


$$
\begin{gathered}
N_{\mathrm{s}}^{A}=2\left(\bar{y}-y^{A B}\right), N_{\mathrm{s}}^{B}=2\left(y^{A B}-y^{u}\right) \\
L_{\mathrm{s}}=\left(\bar{y}-y^{A B}\right)\left(\bar{y}+y^{A B}\right) e^{A}+\left(y^{A B}-y^{u}\right)\left(y^{A B}+y^{u}\right) e^{B}, L_{\mathrm{u}}=4 y^{u} .
\end{gathered}
$$

With (17) and (18) in (16), we arrive at the welfare criterion $W$ as a function of the policy instruments as the objective to be maximized. ${ }^{11}$

The objective is concave, and with similar computations as in the case of a single quality level, the optimum is characterized by the following first-order conditions ${ }^{12}$

$$
\begin{gathered}
w_{\mathrm{s}} \frac{\bar{y}+y^{A B}}{2}-c^{\prime}\left(e^{A}\right)=0 \text { and } w_{\mathrm{s}} \frac{y^{A B}+y^{u}}{2}-c^{\prime}\left(e^{B}\right)=0 \\
-w_{\mathrm{s}} e^{A} y^{A B}+c\left(e^{A}\right)=-w_{\mathrm{s}} e^{B} y^{A B}+c\left(e^{B}\right) \text { and }-w_{\mathrm{s}} e^{B} y^{u}+c\left(e^{B}\right)=-2 w_{\mathrm{u}} .
\end{gathered}
$$

These conditions can be easily interpreted. Conditions (19) say that the quality levels are optimal given the thresholds, that is given the set of students. The marginal gain from a change of the high quality level for the average student, $w_{\mathrm{s}} \frac{\bar{y}+y^{A B}}{2}$, is equal to the marginal costs, $c^{\prime}\left(e^{A}\right)$, and similarly for the low quality level. Conditions (20) say that the ability of the students in each program is optimal given the quality levels proposed. The net gain of the higher quality level relative to the lower level is null for the student with marginal ability $y^{A B}$, and the net gain of the low level of educational quality compared to remaining uneducated is null for the student with marginal ability $y^{u}$.

At the optimal educational levels, surely $y^{u}<y^{A B}<\bar{y}$ as depicted in Fig. 1. To see this, as $c$ is convex, (20) implies $c^{\prime}\left(e^{A}\right) \geq w_{s} y^{A B} \geq c^{\prime}\left(e^{B}\right)$. Plugging $c^{\prime}\left(e^{A}\right) \geq w_{s} y^{A B}$ into the first optimality condition of (19), we obtain $\bar{y} \geq y^{A B}$ and plugging $w_{s} y^{A B} \geq c^{\prime}\left(e^{B}\right)$ into the second optimality condition of (19), we obtain $y^{u} \leq y^{A B}$.

Hence, optimality calls for differentiation. We shall denote by $\left(\bar{e}^{*}, \underline{e}^{*}\right)$ the two different optimal levels of educational quality with $\bar{e}^{*}>\underline{e}^{*}$.

\subsection{Choice of quality levels (noncooperative setting)}

This section considers the situation with informational asymmetries and full mobility of students. As in a closed economy, a government chooses the level of educational quality in its region taking account of the individual decisions. Individuals,

\footnotetext{
11 If the levels of educational quality are identical, the two thresholds coincide, $y^{u}=y^{A B}$, and the welfare depends only on those who decide to become skilled and not on where they study. In particular, welfare is obtained by allocating them according to (17) so that the same expression holds and welfare is continuous.

12 If regions chose more than one level of quality, they would separate ability types of students within the regional borders. The different regional levels of quality would be set optimally relative to the ability ranges. As will be shown in the following, distortions arise only relative to other regions where external effects of the migration of students are not internalized. Thus, the results of the model about the effect of competition about students between regions do not change with regions choosing more than one quality level.
} 
however, face more choices in an open-economy setting and their decisions are affected by the quality levels chosen by both regions. Mobility thus leads to noncooperative interactions between the two regions. Before focusing on the governments' choices, we analyze individuals' decisions.

\subsubsection{Individual choices}

We consider the individual education and migration choices given the two regions' quality levels, $e^{A}$ and $e^{B}$.

A young individual born in region $I, I=A, B$, now not only has to decide whether to study but also where to study. Since wages are constant, the lifetime income of a young person who decides to study in $I$ is $y e^{I} w_{\mathrm{s}}-c\left(e^{I}\right)$. This implies that the maximum lifetime income of a $y$-young individual who decides to become skilled is

$$
V_{\mathrm{s}}(y)=\max \left[y e^{A} w_{\mathrm{s}}-c\left(e^{A}\right), y e^{B} w_{\mathrm{s}}-c\left(e^{B}\right)\right] .
$$

Any difference of lifetime income is only due to different quality levels in the regions of higher education. The lifetime income of an unskilled worker is unchanged and given by $2 w_{\mathrm{u}}$ in both regions. The individual chooses to be skilled if $V_{\mathrm{s}}(y) \geq 2 w_{\mathrm{u}}$.

In the symmetric case where quality levels are equal, $e^{A}=e^{B}=e$, individuals are indifferent between studying in either region. In that case, we shall assume that they split equally (as occurs, for example, if they do not move at all).

Assume now that quality levels differ. Let us consider $e^{A}>e^{B}$. The return to education increases with ability. As a result, the individuals who choose to study in $A$ and not in $B$ are those with high ability and the individuals who stay unskilled are those with low ability. Specifically, let $y^{A B}$ be the type of an individual who is indifferent between studying in $A$ and $B$. It is defined by

$$
y^{A B} e^{B} w_{\mathrm{s}}-c\left(e^{B}\right)=y^{A B} e^{A} w_{\mathrm{s}}-c\left(e^{A}\right)
$$

or

$$
y^{A B}=\frac{c\left(e^{A}\right)-c\left(e^{B}\right)}{w_{\mathrm{s}}\left(e^{A}-e^{B}\right)} .
$$

Analogously, let $y^{u}$ be the type of an individual who is indifferent between studying and not studying. It is defined by

$$
y^{u} e^{B} w_{\mathrm{s}}-c\left(e^{B}\right)=2 w_{\mathrm{u}}
$$

or

$$
y^{u}=\frac{2 w_{\mathrm{u}}+c\left(e^{B}\right)}{w_{\mathrm{s}} e^{B}} .
$$

It follows that for educational levels $e^{A}, e^{B}$ such that $y^{u}<y^{A B}<\bar{y}$, young individuals partition themselves according to their abilities as depicted in Fig. 1. Comparing the 
conditions (23) and (25) with the optimality condition for the thresholds in (20) for given quality levels, $e^{A}, e^{B}$, we see that there is no distortion. Otherwise, if $y^{u}>y^{A B}$ and $y^{A B}<\bar{y}$, no one would choose to be educated in $B$ and if $y^{u}>y^{A B}$ and $y^{A B}>\bar{y}$, no one would choose to be educated. ${ }^{13}$

Whatever situation, the important point is that, as in the case with a single quality level, the private and the social benefits of taking up a given quality level or of remaining unskilled coincide. This yields the following lemma:

Lemma 1 Given quality levels, the choice of the individuals leads to the optimal partition of the ability types.

An immediate consequence is that the optimum can be obtained even without observing ability levels: If the optimal levels of educational quality are implemented, it suffices to let individuals choose whether (and where) to study. These optimal levels can be thought of as resulting from the decisions of a union of regions acting in a cooperative way. Thus, any inefficiency that may result from a noncooperative choice in quality levels is not due to individuals choices.

\subsubsection{The role of return migration}

The decisions of the governments are determined by the criterion on which they base their choices. With migration, population is variable within a region, and a variety of welfare criteria may be studied (see e.g., the discussion in Blackorby et al. 2009). We consider a criterion according to which the government is concerned with the welfare of the residential workers (natives or foreigners). This criterion is called the residence principle. ${ }^{14}$

For the following analysis, it is important to understand the role of return migration for the governmental decisions and welfare. Let us be more precise: Skilled workers are indifferent between working in either region. Those who have studied in their home region do not move after graduation and remain in their home region as skilled workers. If graduated abroad, however, the graduates' migration behavior depends on the return migration rate $\pi$, which denotes the probability with which they return home for work and which can be understood as implicitly capturing mobility costs. The return migration rate $\pi$ is exogenously given and independent of everything else, in particular of the ability type. It determines the skilled labor force in each region as explained in the following.

\footnotetext{
${ }^{13}$ Considering more precisely $y^{u}<y^{A B}$, the inequality does not follow from construction, but depends on the curvature of the cost function and the unskilled wage. From (23) and (25), $y^{A B}$ is larger than $y^{u}$ if $\frac{c\left(e^{A}\right)-c\left(e^{B}\right)}{e^{A}-e^{B}}>\frac{2 w_{u}}{e^{B}}+\frac{c\left(e^{B}\right)}{e^{B}}$. The inequality requires the slope of the cost between $e^{A}$ and $e^{B}$ to be large enough relative to that at $e^{B}$ and the unskilled wage.

${ }^{14}$ According to the natives' principle, the government is concerned with the aggregate wage income of natives working at home or abroad net of educational costs. In our model, the natives' criterion is equivalent, from an analytical point of view, to the residence criterion for the case where all natives return back home after graduation abroad. We will briefly comment on this in Sect. 5.4.
} 
To fix the idea, let us have again $e^{A}>e^{B}$. The top ability students from both regions study in region $A$. Their number is $2\left(\bar{y}-y^{A B}\right)$ as given by (17). Half of the students in $A$ come from region $B$, and among those a proportion $\pi \in[0,1]$ returns back to their home region $B$ after graduation as skilled workers. Hence, only the fraction $1-\pi / 2$ of skilled workers with quality level $e^{A}$ works in $A$ and the remaining fraction, $\pi / 2$, works in $B$. Similarly, the low-ability students of both regions study in region B. Their total number is $2\left(y^{A B}-y^{u}\right)$, and among those a fraction $\pi / 2$ will work in region $A$ and the fraction $1-\pi / 2$ in region $B$.

The residential welfare of a region is defined as the aggregate lifetime income of the residents. There are three types of workers: the skilled workers with quality levels $e^{A}$ or $e^{B}$, respectively, and the unskilled workers. The lifetime income of all unskilled workers in a region is $2 w_{\mathrm{u}} y^{u}$. Since the cost of education is entirely borne by the students, the lifetime income of a skilled worker is defined as his wage income net of the cost of education. To simplify notation, let $Y^{I}$ denote the lifetime income of all skilled workers with quality level $e^{I}$. We have

$$
\begin{gathered}
W^{A}\left(e^{A}, e^{B}\right)=\left(1-\frac{\pi}{2}\right) Y^{A}+\frac{\pi}{2} Y^{B}+2 w_{\mathrm{u}} y^{u}, \\
W^{B}\left(e^{A}, e^{B}\right)=\frac{\pi}{2} Y^{A}+\left(1-\frac{\pi}{2}\right) Y^{B}+2 w_{\mathrm{u}} y^{u} .
\end{gathered}
$$

The interpretation is straightforward: Region $A$ keeps $1-\pi / 2$ of the students who were educated in the region and $\pi / 2$ of those who studied in $B$, and similarly for region $B$. More generally, the larger the return migration rate is, the less the skilled labor force in a region depends on the region's decision. At one extreme, where the return migration rate is null $(\pi=0)$, each region ends up with the skilled labor force that graduated in that region. This opens up the possibility of competition for students. At the other extreme, where the return migration rate is $1(\pi=1)$, each region ends up with its natives' labor force. In the intermediate case, with $\pi$ between 0 and 1 , welfare of each region is a combination of welfare obtained in each of the two extreme cases. From (26), we can write

$$
W^{A}\left(e^{A}, e^{B}\right)=(1-\pi)\left[Y^{A}+2 w_{\mathrm{u}} y^{u}\right]+\pi\left[\frac{1}{2}\left(Y^{A}+Y^{B}\right)+2 w_{\mathrm{u}} y^{u}\right] .
$$

The first term in square brackets is the welfare of $A$ for $\pi$ equal to zero, and the second term corresponds to the welfare of $A$ for $\pi$ equal to one. Thus, $W^{A}$ can be written as $(1-\pi) W_{\mid \pi=0}^{A}+\pi W_{\mid \pi=1}^{A}$ where $W_{\mid \pi=0}^{A}$ and $W_{\mid \pi=1}^{A}$ are the welfare levels in the two extreme cases, $\pi=0$ and $\pi=1$, respectively. As this is also true for $B$, we obtain

$$
W^{I}\left(e^{A}, e^{B}\right)=(1-\pi) W_{\mid \pi=0}^{I}\left(e^{A}, e^{B}\right)+\pi W_{\mid \pi=1}^{I}\left(e^{A}, e^{B}\right) \quad I=A, B .
$$

The values for $Y^{A}$ and $Y^{B}$ remain to be spelled out. Take $e^{A}>e^{B}$ (the case $e^{A}<e^{B}$ is symmetric). The average effective labor supply of a skilled worker with quality level $e^{A}$ is $\frac{\bar{y}+y^{A B}}{2} e^{A}$, which yields an average lifetime income equal to $w_{\mathrm{s}} \frac{\bar{y}+y^{A B}}{2} e^{A}-c\left(e^{A}\right)$. Similarly, the average effective labor supply of a skilled worker with quality level 
$e^{B}$ is $\frac{y^{A B}+y^{u}}{2} e^{B}$, which yields an average lifetime income equal to $w_{\mathrm{s}} \frac{y^{A B}+y^{u}}{2} e^{B}-c\left(e^{B}\right)$. Weighting by the number of students in $A, 2\left(\bar{y}-y^{A B}\right)$, or in $B, 2\left(y^{2} A B-y^{u}\right)$, we obtain for $e^{A}>e^{B}$

$$
\begin{gathered}
Y^{A}=2\left(\bar{y}-y^{A B}\right)\left[w_{\mathrm{s}} \frac{\bar{y}+y^{A B}}{2} e^{A}-c\left(e^{A}\right)\right] \\
Y^{B}=2\left(y^{A B}-y^{u}\right)\left[w_{\mathrm{s}} \frac{y^{A B}+y^{u}}{2} e^{B}-c\left(e^{B}\right)\right] .
\end{gathered}
$$

For the following analysis, it is useful to determine students' behavior for almost identical quality levels in both regions and to understand the benefits of differentiation.

\subsubsection{Scope for differentiation}

We want to study here whether differentiation is possible and beneficial. Marginal changes in quality levels in a neighborhood of a symmetric situation have a dramatic selection effect on the students. To make this precise, consider the type of an individual who is indifferent between studying in $A$ and $B, y^{A B}$, as $e^{A}$ and $e^{B}$ are very close. Making the quality levels converge to $e$, the limits of $y^{A B}$ from above or below $e$ are given by

$$
\lim _{e^{A} \rightarrow e^{+}} \frac{c\left(e^{A}\right)-c(e)}{w_{\mathrm{S}}\left(e^{A}-e\right)}=\lim _{e^{B} \rightarrow e^{-}} \frac{c(e)-c\left(e^{B}\right)}{w_{\mathrm{S}}\left(e-e^{B}\right)}=\frac{c^{\prime}(e)}{w_{\mathrm{S}}} .
$$

We denote this limit by $y^{\lim }(e)$

$$
y^{\lim }(e)=\frac{c^{\prime}(e)}{w_{\mathrm{s}}} .
$$

Starting from identical levels $(e, e)$, regions share equally the students, i.e., the individuals with ability above $y^{u}$. By marginally increasing its level $e^{A}$ above $e$, region $A$ attracts all top ability students, those with ability larger than $y^{\lim }(e)$, and $B$ attracts those with ability between $y^{u}$ and $y^{\lim }(e)$. Thus, a massive reallocation of students takes place. If a region, say $B$, decreases its level below $e$, the analysis is similar, but there is also a marginal change in the unskilled level $y^{u}$ since it is determined by the smaller level $e^{B}$ (as given by (25)).

Such an analysis is true provided $e$ is not too extreme. Specifically, the thresholds given by (23) and (25) are valid if $\bar{y}>y^{A B}>y^{u}$. These inequalities are satisfied for quality levels close to $e$ if

$$
\bar{y}>\frac{c^{\prime}(e)}{w_{\mathrm{s}}}>\frac{2 w_{\mathrm{u}}+c(e)}{w_{\mathrm{s}} e} .
$$


When inequalities (34) hold, we say that there is scope for differentiation at $e$.

In order to see whether differentiation is not only possible, but also beneficial let us look at total welfare. Specifically, let $T W\left(e^{A}, e^{B}\right)$ denote the total welfare associated with the two quality levels, $e^{A}, e^{B}$. We have

$$
T W\left(e^{A}, e^{B}\right)=Y^{A}+Y^{B}+4 w_{\mathrm{u}} y^{u}
$$

and the identity

$$
T W\left(e^{A}, e^{B}\right)=W^{A}\left(e^{A}, e^{B}\right)+W^{B}\left(e^{A}, e^{B}\right) .
$$

It is useful to note that total welfare is independent of the return migration rates. These rates matter only because they determine the shares of this total welfare assigned to the two regions, which affect a region's incentive to choose a quality level.

Referring back to the case-identified above-where there is scope for differentiation, it turns out that not only differentiation is then possible, but it is also beneficial, as stated in the following lemma.

Lemma 2 Total welfare TW is continuous in quality levels. It is maximal at $\left(\bar{e}^{*}, \underline{e}^{*}\right)$. Furthermore, assume that there is scope for differentiation at e, i.e., that (34) holds. Then,

$$
\lim _{e^{A} \rightarrow e^{+}} \frac{\partial T W}{\partial e^{A}}\left(e^{A}, e\right)=w_{\mathrm{s}}\left(\bar{y}-\frac{c^{\prime}(e)}{w_{\mathrm{s}}}\right)^{2}, \lim _{e^{B} \rightarrow e^{-}} \frac{\partial T W}{\partial e^{B}}\left(e, e^{B}\right)=-w_{\mathrm{s}}\left(\frac{c^{\prime}(e)}{w_{\mathrm{s}}}-y^{u}\right)^{2}
$$

where $y^{u}=\frac{2 w_{\mathrm{u}}+c(e)}{w_{\mathrm{s}} e}$. As a result, there are strong benefits from differentiation.

Proof See Appendix 1.

The fact that the optimum can be obtained even without observing ability levels explains why the maximum of $T W$ is obtained at $\left(\bar{e}^{*}, \underline{e}^{*}\right)$. We emphasize the continuity property of total welfare even at symmetric levels $(e, e)$ : Students reallocate between the two regions, and still each individual lifetime income is continuous in the quality levels, hence total welfare as well. Instead, when we consider regions' individual welfare the reallocation of students will generate discontinuities in their levels, and the jumps will be in the opposite direction (since the sum of the regions' welfare, $T W$, is continuous). According to (37), $\frac{\partial T W}{\partial e^{A}}\left(e^{A}, e\right)$ is positive for $e^{A}$ sufficiently close to $e$ but larger than $e$ : Starting from a symmetric situation, increasing slightly the quality level $e^{A}$ above $e$ typically increases welfare. Similarly, since $\frac{\partial T W}{\partial e^{B}}\left(e, e^{B}\right)$ is negative for $e^{B}$ sufficiently close to $e$ but smaller than $e$, decreasing slightly the quality level of $B$ below $e$ increases welfare (of course similar results are obtained by exchanging the roles of $A$ and $B$, i.e., if $e^{A}$ is decreased or $e^{B}$ is increased). Hence, there is a benefit from differentiation, whatever the direction, as long as differentiation is possible. 


\section{Government decisions with different degrees of return migration}

This section analyzes the chosen quality levels and their optimality, focusing in particular on how the return migration rates affect the resulting equilibrium quality levels.

\subsection{The case of full return migration}

The government is concerned with the well-being of its residents who, for $\pi=1$, are all natives who have either stayed or returned back home after their graduation abroad.

As both regions are assumed to be identical, the number of skilled and unskilled labor is also identical in both regions and so is welfare amounting to one half of total welfare $T W$

$$
\begin{aligned}
W_{\mid \pi=1}^{A}\left(e^{A}, e^{B}\right)= & W_{\mid \pi=1}^{B}\left(e^{A}, e^{B}\right)=\frac{1}{2} T W\left(e^{A}, e^{B}\right) \\
= & \left(\bar{y}-y^{A B}\right)\left(w_{\mathrm{s}} \frac{\bar{y}+y^{A B}}{2} e^{A}-c\left(e^{A}\right)\right) \\
& +\left(y^{A B}-y^{u}\right)\left(w_{\mathrm{s}} \frac{y^{A B}+y^{u}}{2} e^{B}-c\left(e^{B}\right)\right)+2 w_{\mathrm{u}} y^{u} .
\end{aligned}
$$

\subsubsection{Incentives for differentiation}

A region's welfare is thus given by half of the total welfare. How total welfare reacts to a change in a quality level provides insights into the region's incentive to differentiate its quality level. Specifically, using the symmetry of total welfare with respect to quality levels and the fact that $W_{\mid \pi=1}^{A}\left(e^{A}, e\right)=T W\left(e^{A}, e\right) / 2$, we deduce from Lemma 2

$$
\lim _{e^{A} \rightarrow e^{-}} \frac{\partial W_{\mid \pi=1}^{A}}{\partial e^{A}}\left(e^{A}, e\right)=-\frac{w_{\mathrm{s}}}{2}\left(\frac{c^{\prime}(e)}{w_{\mathrm{s}}}-y^{u}\right)^{2}, \lim _{e^{A} \rightarrow e^{+}} \frac{\partial W_{\mid \pi=1}^{A}}{\partial e^{A}}\left(e^{A}, e\right)=\frac{w_{\mathrm{s}}}{2}\left(\bar{y}-\frac{c^{\prime}(e)}{w_{\mathrm{s}}}\right)^{2} .
$$

Hence, taking the point of view of region $A$ when region $B$ 's quality level is fixed at $e$, we have that $e^{A} \rightarrow W_{\mid \pi=1}^{A}\left(e^{A}, e\right)$ has a local minimum at $e^{A}=e$ with a kink: A region benefits from decreasing its level below that of the other region and also from increasing it. There is a strong force toward differentiation, and a symmetric situation is not an equilibrium. Actually, regions choose the optimal differentiation levels at equilibrium, as stated in the following proposition.

Proposition 1 If all graduates return to their home region $(\pi=1)$, optimally differentiated quality levels, $\left(\bar{e}^{*}, \underline{e}^{*}\right)$ or $\left(\underline{e}^{*}, \bar{e}^{*}\right)$, form a Nash equilibrium. There is no other Nash equilibrium. 
Proof The proof that optimal differentiation is a Nash equilibrium is straightforward. By recognizing that in each region welfare is just half of total welfare, it is obvious that the incentives of both regions and the social planner are aligned. As a result, if one region chooses one of the optimal levels, say the larger one, $\bar{e}^{*}$, the other region's optimal choice is the lower one, $\underline{e}^{*}$, and vice versa. For the proof of uniqueness see the proof section (Appendix 1).

The intuition for this result is that with a return probability of one both regions have the same labor force wherever the workers have been educated and are concerned by efficiency considerations only, as illustrated in Appendix 2.

We can summarize. When regions take account of their residents and all students return to their home region after graduation $(\pi=1)$, there are strong forces to differentiate the educational quality. Whatever the decision, the result in terms of welfare is the same for the region because the students return home and both regions share the same labor force with the same ability composition. The resulting equilibrium of differentiated quality levels is unique and optimal.

\subsection{The case of no return migration}

This section considers the extreme scenario in which all students who study abroad stay there after graduation, $\pi=0$.

With different quality levels, $e^{A}>e^{B}$, income levels $Y^{A}$ and $Y^{B}$ are given by (30) and (31). With $\pi=0$, the welfare criteria (26) and (27) are

$$
\begin{gathered}
W_{\mid \pi=0}^{A}=w_{\mathrm{s}}\left(\bar{y}-y^{A B}\right)\left(\bar{y}+y^{A B}\right) e^{A}+2 y^{u} w_{\mathrm{u}}-2 c\left(e^{A}\right)\left(\bar{y}-y^{A B}\right) \\
W_{\mid \pi=0}^{B}=w_{\mathrm{s}}\left(y^{A B}-y^{u}\right)\left(y^{A B}+y^{u}\right) e^{B}+2 y^{u} w_{\mathrm{u}}-2 c\left(e^{B}\right)\left(y^{A B}-y^{u}\right),
\end{gathered}
$$

and in the symmetric case where both regions choose the same level of educational quality, $e$, welfare in each region amounts to

$$
W_{\mid \pi=0}^{A}=W_{\mid \pi=0}^{B}=w_{\mathrm{s}}\left(\bar{y}-y^{u}\right)\left(\bar{y}+y^{u}\right) \frac{e}{2}+2 y^{u} w_{\mathrm{u}}-c(e)\left(\bar{y}-y^{u}\right) .
$$

Now, the competition for students, who will work as skilled workers in their region of education, plays an important role in the choices of the educational quality levels. This competition is especially harsh when the quality levels of the two regions approach one another. The massive reallocation of students around symmetric quality levels generates discontinuities in the welfare levels of the regions and incentives for differentiation. This is not true, however, at a level denoted by $\hat{e}$, which will be important in the subsequent analysis.

To illustrate this, we first analyze the situation where regions choose the optimal quality level of a closed economy and then open up their borders for mobile students. We then analyze the resulting Nash equilibria. 


\subsubsection{Incentives for differentiation}

Let each region choose the single-constrained optimal level $e^{*}$ of a closed economy given by (11). We show that a marginal increase is profitable to a region. The following reasoning is illustrated in Fig. 2. At the optimum $e^{*}$, the marginal gain from a change in the quality level for the average student, $w_{\mathrm{s}} \frac{\bar{y}+y^{*}}{2}$, is equal to the marginal cost, $c^{\prime}\left(e^{*}\right)$. This implies that $e^{*}$ is 'too high' for the marginal student with ability $y^{*}$ and 'too low' for the top ability student. ${ }^{15}$ It follows that if region $A$ increases slightly its quality level, the set of students split into two parts with $A$ attracting the top ability students. The set of individuals who decide to study is unchanged, $y^{u}=y^{*}$.

To assess the possible benefits for $A$, consider the type of an individual who is indifferent between studying in $A$ and $B, y^{A B}$, satisfying $y^{A B} e^{A} w_{\mathrm{s}}-c\left(e^{A}\right)=y^{A B} e^{*} w_{\mathrm{s}}-c\left(e^{*}\right)$. Observe that by convexity of $c(e)$ we have that

$$
y^{A B}=\frac{c\left(e^{A}\right)-c\left(e^{*}\right)}{w_{\mathrm{s}}\left(e^{A}-e^{*}\right)} \geq \frac{c^{\prime}\left(e^{*}\right)}{w_{\mathrm{s}}}=\frac{\bar{y}+y^{*}}{2}
$$

where the last equality follows from the optimality conditions (Fig. 2). Hence, region $A$, by providing a higher educational quality level than $B$, not only attracts the best students but also deters half of the students with low abilities at least. This is true whatever the level $e^{A}$ strictly larger than $e^{*}$. Taking the limit of $y^{A B}$ when $e^{A}$ tends to $e^{*}$ gives

$$
y^{\lim }\left(e^{*}\right)=\frac{c^{\prime}\left(e^{*}\right)}{w_{\mathrm{s}}}=\frac{\bar{y}+y^{*}}{2} .
$$

Recall that, if $A$ increases slightly its quality level, the overall set of individuals who decide to study is unchanged and given by the individuals whose ability is larger than $y^{*}$. Thus, individuals with ability larger than the average over all students, that is those with ability in $\left(\frac{\bar{y}+y^{*}}{2}, \bar{y}\right)$, study in $A$, and individuals with ability lower than the average, those with ability in $\left(y^{*}, \frac{\bar{y}+y^{*}}{2}\right)$, study in $B$. In words, for $e^{A}$ arbitrarily close but larger than $e^{*}, A$ has the same number of students as at the initial situation, but the ability composition has improved. This results in an improvement in welfare in region $A$. Simple computation gives that welfare is increased by

$$
w_{\mathrm{s}}\left(\frac{\bar{y}-y^{*}}{2}\right)^{2} e^{*}
$$

More generally, there is a discontinuity when the quality levels are equalized. The reason is student mobility and the resulting change in the skilled labor force. Thus,

\footnotetext{
15 Specifically, consider the lifetime income of a young individual with ability $y, y e w_{\mathrm{s}}-c(e)$, as a function of $e$. It is concave in $e$ with a derivative given by $y w_{\mathrm{s}_{-}}-c^{\prime}(e)$. For $y=y^{*}$, this derivative is negative at $e=e^{*}, y^{*} w_{\mathrm{s}}-c^{\prime}\left(e^{*}\right)<0$, since $c^{\prime}\left(e^{*}\right)$ is equal to $w_{\mathrm{s}} \frac{\bar{y}+y^{*}}{2}$. Thus, the lifetime income $y^{*} e w_{\mathrm{s}}-c(e)$ decreases with $e$ at $e=e^{*}$ : A student with ability $y^{*}$ prefers a (slightly) lower educational quality level than $e^{*}$. At the opposite, $\bar{y} w_{\mathrm{s}}-c^{\prime}\left(e^{*}\right)>0$, and a similar argument yields that students with large enough ability strictly prefer a larger quality level than $e^{*}$.
} 


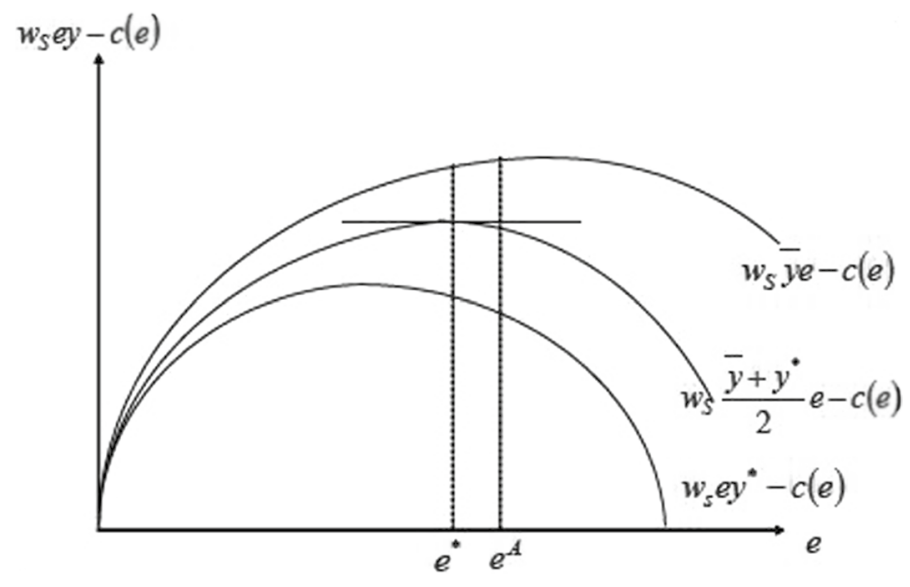

Fig. 2 The sorting of ability types to regions with a single-constrained quality level

the forces toward differentiation are strong. We now study how this affects the equilibrium.

\subsubsection{Nash equilibrium}

By the same computation as in (44), a region that increases marginally its quality level attracts all students with ability larger than the value $y^{l i m}=c^{\prime}(e) / w_{\mathrm{s}}$. Similarly, a region that decreases marginally its level attracts all students with ability lower than this value. There are overall the same number of students as in the symmetric situation ( $y^{u}$ changes marginally and only if one region decreases its level), but the ability composition of those who study in $A$ or in $B$ is affected. When the net benefit from educating high-ability students, those with ability larger than $y^{\text {lim }}$, is strictly larger than the net benefit from educating low-ability students, those with ability between $y^{l i m}$ and $y^{u}$, increasing marginally the quality level above that of the other region so as to attract the high-ability students is surely beneficial. This was shown to be the case at the optimal single level $e^{*}$. Similarly, when the net benefit from educating low-ability students is larger than that from educating high-ability students, a region surely benefits from choosing a quality level slightly below that of the other region. There is a (unique) level, denoted by $\hat{e}$, for which these benefits are equalized. Such a level is larger than $e^{*}$ and is the only possible candidate for a symmetric equilibrium in pure strategies. We will make this precise in the following.

The next lemma analyzes the welfare of a region when its quality level is close to the other region's level. Consider region $A$, for example. Keeping the quality level $e^{B}$ fixed at $e$, we start with a lower level in region $A$ and increase it. When $e^{A}$ reaches $e, A$ and $B$ share the students equally, and by symmetry $A$ 's welfare $W_{\mid \pi=0}^{A}(e, e)$ equals half of the total welfare $\frac{1}{2} T W(e, e)$. This may generate a jump in region $A^{\prime}$ 's welfare, measured by $\frac{1}{2} T W(e, e)-\lim _{e^{A} \rightarrow e^{-}} W_{\mid \pi=0}^{A}\left(e^{A}, e\right)$. When $e^{A}$ becomes larger than $e$, the roles of $A$ and $B$ are exchanged with $A$ now attracting 
the high-ability students. Hence, there may be another jump. According to the next lemma, these two jumps are equal, in particular they are of the same sign.

Lemma 3 The jumps in region A's welfare when $e^{A}$ approaches e from below or from above are equal

$$
\frac{1}{2} T W(e, e)-\lim _{e^{A} \rightarrow e^{-}} W_{\mid \pi=0}^{A}\left(e^{A}, e\right)=\lim _{e^{A} \rightarrow e^{+}} W_{\mid \pi=0}^{A}\left(e^{A}, e\right)-\frac{1}{2} T W(e, e) .
$$

At a symmetric equilibrium, the jumps must be null.

Proof See Appendix 1.

The term on the left-hand side measures the gain in $A$ 's welfare as $A$ increases its level to $B$ 's level from below, and the term on the right-hand side is the loss in $A$ 's welfare as $A$ decreases its level to $B$ 's level from above.

The intuition behind the lemma is the following one. The sum of the two regions' welfare depends on the levels of $e^{A}$ and $e^{B}$ in a continuous way, which implies that around symmetric levels $(e, e)$, regions are playing approximately a constant two-person game. The ability composition of those who study in $A$ or in $B$, however, depends on which level is larger and affects the share of the total welfare received by each region. The jump up in $A$ 's welfare when $e^{A}$ approaches $e$ from above is exactly compensated by the jump down in $B$ 's welfare. Exchanging the role of $A$ and $B$ gives the result.

There is a unique value $\hat{e}$ for which the jumps are null. At this level, the net benefit from educating high-ability students with ability larger than $y^{A B}$ is exactly equal to the net benefit from educating low-ability students with ability between $y^{A B}$ and $y^{u}$. By definition, the value of $W_{\mid \pi=0}^{A}\left(e^{A}, \hat{e}\right)$ is close to $\frac{1}{2} T W(\hat{e}, \hat{e})$ for $e^{A}$ close to $\hat{e}$, and the same for $B$ by symmetry.

Under some conditions on the cost function, the level $\hat{e}$ gives rise to an equilibrium, which is furthermore the unique equilibrium.

Proposition 2 Assume that all graduates stay where they were educated $(\pi=0)$. If regions start with the optimal quality level in a closed economy and open up their borders, students' mobility induces regions to increase the quality level above this optimal level. With a quadratic cost function, an equilibrium in pure strategies is symmetric. Regions choose both the same quality level $\hat{e}$, larger than $e^{*}$.

\section{Proof See Appendix 1.}

Thus, in the case where an equilibrium is necessarily symmetric, as for a quadratic cost function, the outcome is worse than in the closed economy case. When no differentiation occurs at equilibrium, opening the borders and introducing competition for students can only impair welfare if the starting situation was the optimal one in a closed economy. Competition for students leads to a too high quality of education and too few students. (See Appendix 2 for an illustration.) 
After having studied the two extreme cases of full and no return migration, we analyze in the following the case of partial return migration of foreign students.

\subsection{The case of partial return migration}

For the intermediate case of partial return migration, $0<\pi<1$, we can see that the welfare of each region is a combination of the welfare obtained in each extreme case, as given by (29)

$$
W^{I}\left(e^{A}, e^{B}\right)=(1-\pi) W_{\mid \pi=0}^{I}+\pi W_{\mid \pi=1}^{I}\left(e^{A}, e^{B}\right) I=A, B .
$$

Hence, the insights from the two extreme cases will be helpful in the analysis of partial return migration.

If some foreign students stay in the region after graduation, competition for students is beneficial. First, we show that this competition induces a force toward less differentiation than is optimal. In particular, the optimal differentiation levels $\bar{e}^{*}, \underline{e}^{*}$ do not form a Nash equilibrium. Second, if the return probability of foreign students is small enough, symmetric educational quality levels are a Nash equilibrium in pure strategies.

\subsubsection{Asymmetric Nash equilibrium and optimal differentiation}

Consider the optimally differentiated levels with, for instance, $A$ choosing the highest level: $e^{A}=\bar{e}^{*}$ and $e^{B}=\underline{e}^{*}$. Let region $A$ contemplate changing its quality level. From Section 5.1, we know that for $\pi=1$ the optimally differentiated educational levels are chosen in the Nash equilibrium. Hence, the marginal change of welfare for $\pi=1$ by changing $e^{A}$ is zero at the point of optimal differentiation. From the representation of welfare as a convex combination of the two extreme cases in (46), we can now infer that the change in welfare at the point of optimal differentiation only depends on the change of welfare for $\pi=0$.

The forces toward more convergence or more differentiation can be analyzed more generally by considering marginal changes starting at unequal levels, say $e^{A}>e^{B}$ (assuming that each region educates some students, i.e., $0<y^{u}<y^{A B}<\bar{y}$ ). As long as we consider variations in quality levels that are small enough so that the quality level in $A$ is still higher than in $B, A$ continues to attract the students with the highest ability. Hence, a marginal change in $e^{A}$ or in $e^{B}$ modifies the allocation of the students at the margin only through the modifications of the thresholds $y^{A B}$ and $y^{u}$. From the convexity of the cost function $c$, increasing $e^{A}$ or increasing $e^{B}$ increases the threshold value $y^{A B}$, meaning here that the number of students in $B$ increases. As for $y^{u}$, it is independent of $e^{A}$.

A marginal change in $e^{A}$ yields the marginal change in $W_{\mid \pi=0}^{A}$

$$
\frac{\partial W_{\mid \pi=0}^{A}}{\partial e^{A}}\left(e^{A}, e^{B}\right)=2\left(\bar{y}-y^{A B}\right)\left[w_{\mathrm{s}} \frac{\bar{y}+y^{A B}}{2}-c^{\prime}\left(e^{A}\right)\right]+2\left[y^{A B} e^{A} w_{\mathrm{s}}-c\left(e^{A}\right)\right]\left(-\frac{\partial y^{A B}}{\partial e^{A}}\right) .
$$


The marginal change is composed of two terms. The first term reflects the efficiency gains (possibly negative) for the current population of students in $A$ that result from changing the quality level. The second term reflects the migration effect that results from changes in that population through the modification of the threshold. It is equal to the change in the number of students, $-2 \frac{\partial y^{A B}}{\partial e^{A}}$, multiplied by the lifetime income per such student $\left[y^{A B} e^{A} w_{\mathrm{s}}-c\left(e^{A}\right)\right]$. Observe that this lifetime income is surely positive; hence, the second term in (47) is always negative. As a result, region $A$ prefers a lower quality level than the one that would maximize the efficiency gains (given the level $e^{B}$ ) so as to attract more students. This readily explains why the optimal educational values do not form an equilibrium: Given that $B$ chooses $\underline{e}^{*}$, region $A$ prefers a lower quality level than the optimal $\bar{e}^{*}$.

Similarly, a marginal change in the lowest quality level $e^{B}$ yields the marginal change in $W_{\mid \pi=0}^{B}$

$$
\begin{aligned}
\frac{\partial W_{\mid \pi=0}^{B}}{\partial e^{B}}\left(e^{A}, e^{B}\right)= & 2\left(y^{A B}-y^{u}\right)\left[w_{\mathrm{s}} \frac{y^{A B}+y^{u}}{2}-c^{\prime}\left(e^{B}\right)\right]+2\left[y^{A B} e^{B} w_{\mathrm{s}}-c\left(e^{B}\right)\right] \frac{\partial y^{A B}}{\partial e^{B}} \\
& +2\left[y^{u} e^{B} w_{\mathrm{s}}-w_{\mathrm{u}}-c\left(e^{B}\right)\right]\left(-\frac{\partial y^{u}}{\partial e^{B}}\right) .
\end{aligned}
$$

The marginal change in welfare is now composed of three terms: the efficiency gains for the students in $B$ (first term), a migration effect due to students moving from $B$ to $A$ (second term), and a change in the incentives to become skilled (third term).

The efficiency gains and the migration effects can be similarly interpreted as for $A$. Observe that the migration effect is exactly the opposite of the one for $A$ : The impact of the change in the population of the students between $A$ or $B$ results in a simple transfer of welfare between the two regions at the margin. The reason is that the attracted students who move from one region to another have roughly the same lifetime income in both regions. This can be checked by noticing that $y^{A B} e^{B} w_{\mathrm{s}}-c\left(e^{B}\right)=y^{A B} e^{A} w_{\mathrm{S}}-c\left(e^{A}\right)$ (by the arbitrage condition (23) for the marginal student $y^{A B}$ ) and $\frac{\partial y^{A B}}{\partial e^{A}}=\frac{\partial y^{A B}}{\partial e^{B}}$. Thus, the second term is always positive and provides an incentive to increase the quality level above the efficient one (given $\left.e^{A}\right)$.

A change in the lowest quality level has an additional impact on the incentives to become skilled, as reflected by the third term in (48). Observe that a marginal change in $e^{B}$ has a null overall marginal impact on the welfare of the marginal students by the arbitrage condition for students with ability $y^{u}$. This is, however, not the case for $B$ because this arbitrage condition (25) yields $\left[y^{u} e^{B} w_{\mathrm{s}}-w_{\mathrm{u}}-c\left(e^{B}\right)\right]=w^{u}$. Hence, the third term is not null. The reason is that unskilled individuals are immobile. Hence, an increase in the number of students has a positive impact on $B$ due to the migration of unskilled citizens from $A$ who become students in $B$. The welfare benefit to $B$ is equal to the lifetime gain of these marginal students, $2 w^{u}$, multiplied by the marginal increase in students (coming from $A$ ), $-\frac{\partial y^{u}}{\partial e^{B}}$. This explains the third term. Thus, region $B$ has an additional incentive to increase its quality level when this increases the incentive to study, i.e., when $\frac{\partial y^{u}}{\partial e^{B}}<0$. In that case, increasing the quality level above the efficient one allows $B$ to attract students both at the bottom and at the top of its students' 
population. If instead $\frac{\partial y^{u}}{\partial e^{B}}>0$, the third term is negative and diminishes the force to convergence. How the value $y^{u}$ changes is ambiguous. In the proof of Proposition 3 , we derive a condition under which the region with the lowest quality level has an incentive to increase its level above the optimal one.

To sum up, competition about the marginal students who are close to being indifferent between the two regions is a force toward less differentiation. However, attracting additional workers by inducing them to become skilled may be a countervailing effect for a region which chooses a low quality level.

We can derive the following proposition:

Proposition 3 Assume that $\pi<1$. Optimally differentiated educational quality levels do not constitute an equilibrium. Suppose for example that $\left(e^{A}, e^{B}\right)=\left(\bar{e}^{*}, \underline{e}^{*}\right)$, region $A$ has an incentive to choose a quality level less than $\bar{e}^{*}$. Furthermore, if the optimal differentiation is not too large, $\underline{e}^{*}>\frac{\bar{e}^{*}}{2}$, then region $B$ has an incentive to choose a quality level higher than $\underline{e}^{*}$.

\section{Proof See Appendix 1.}

The intuition for this result is that a region takes into account the impact of its quality level on foreign students who only partially return to their home region. Since the attracted students are indifferent between the two quality levels, there is no welfare loss on the aggregate. Those foreign students who stay in the region where they have been educated have the same lifetime income at the margin which results in a transfer of welfare from their home region to the region of education. The region with the highest quality level has an incentive to decrease this level in order to attract higher ability types of students from the other region. The region with the lowest quality level has an incentive to increase this level so that the threshold ability level and the number of students increase.

The welfare implications can be explained by externalities due to student mobility. If region $A$ with the highest quality level increases its quality level, the lower ability range of its students moves to region $B$. This creates a positive externality on region $B$ because it increases the number of students and improves their ability composition in region $B$. As a result, region $A$ chooses a quality level which is lower than optimal. If region $B$ with the lowest quality level increases this level, it attracts the lower range of ability types of region $A$. This imposes a negative externality on region $A$ which loses students. Hence, region $B$ chooses a higher quality level than the optimal one.

As the forces toward competition depend on $\pi$, the equilibrium choices do as well. We can safely conjecture that, under the conditions stated in Proposition 3, there is an equilibrium with differentiated quality levels for $\pi$ close enough to 1 . Hence, even though the regions are symmetric, differentiation arises in the equilibrium. In addition, differentiation is lower than the efficient one in the sense that $\underline{e}^{*}<e^{B}<e^{A}<\bar{e}^{*}$, assuming that $A$ provides the larger level. 


\subsubsection{Symmetric Nash equilibrium}

Now, we turn to the analysis of symmetric quality levels. Recall that a region's welfare, say $A$ 's welfare, is continuous for $\pi=1$ keeping the other region's quality level fixed at $e^{B}$. Instead, for $\pi=0$, the welfare is discontinuous when the quality levels become equalized as stated in Lemma 3 except if $e^{B}$ is set equal to $\hat{e}$. Hence, the welfare in the intermediate case $0<\pi<1$ is also discontinuous and Lemma 3 is valid for any $\pi$ smaller than 1 . The following proposition shows that the stronger the competition for students (the smaller $\pi$ ), the stronger the forces toward the equalization of the quality levels.

Proposition 4 Whatever the value of $\pi, \pi<1,(\hat{e}, \hat{e})$ is the unique candidate for a symmetric equilibrium:

(a) It is not an equilibrium when the return probability is too large, that is close to 1.

(b) If $(\hat{e}, \hat{e})$ is an equilibrium for some $\pi$, then it is also an equilibrium when graduates' return probability is lower, that is for any value smaller than $\pi$.

Proof See Appendix 1.

Summing up, these results show that for return probabilities close to, but smaller than unity, any Nash equilibrium is asymmetric and differentiation is smaller than would be optimal. The reason is externalities stemming from student mobility. However, for low return probabilities a Nash equilibrium may be symmetric and the quality level in both regions is larger than the optimal level in closed economies. In this case, regions forgo the possible gain in welfare due to differentiation because the low return migration of students prompts them to compete for students by equalizing their quality levels. Appendix 2 provides an illustration.

\subsection{Comments on the choice of the welfare criterion}

Let us conclude this section by commenting on the sensitivity of the results to the chosen welfare criterion.

First, the welfare criterion is based on aggregate lifetime income. Without performing a full-fledged analysis, we want to assess how the results derived above can be expected to change when a per-capita criterion is chosen instead. When all graduates return home after their studies abroad, $\pi=1$, the optimally differentiated quality levels are again chosen. There is no competition for students and both regions are only concerned about efficiency considerations.

With a positive probability that foreign graduates stay abroad, $\pi<1$, competition effects are present both with an aggregate and with a per-capita welfare criterion. But given that the number of workers is not relevant with a per-capita criterion, intuitively, it is more important with that criterion to attract and keep individuals with 
above-average skill units, taking the costs of education into account when appropriate. To put it differently, with an aggregate welfare criterion, there is a "number-effect" which works toward a lower level of educational quality, ceteris paribus, while this effect is missing with a per-capita criterion.

There is thus a larger incentive for the region with the highest level of educational quality, say $A$, to raise $e^{A}$, when per-capita welfare is maximized compared to aggregate welfare. For region $B$, the incentive to raise $e^{B}$ instead is diminished because only the quality and not the number of students coming from $A$ and staying in $B$ counts. This points to more differentiation; however, the quality level $e^{B}$ has an additional impact on the incentives to become skilled, which can go in either direction as we have seen in Sect. 5.3.1. Following from the above argument, a symmetric choice of the quality level by both regions cannot be an equilibrium with a per-capita criterion when $\pi<1$. There is always the incentive for, say, region $A$ to increase $e^{A}$ in order to attract the better half of the students.

Second, the welfare criterion is based on the residence principle. According to the natives' principle, the government is concerned with the aggregate wage income of natives working at home or abroad net of educational costs. For this criterion, there is thus no need to consider different return migration rates as they do not change the relevant population. In our model, the natives' criterion is equivalent, from an analytical point of view, to the residence criterion when all natives return back home after graduation. Given this equivalence, we can compare the outcomes for the natives' criterion with the outcomes for the residence criterion with only partial or no return migration by comparing the outcomes for the residence criterion with full return migration (which is equivalent with the outcomes for the natives' criterion) to the outcomes for the residence criterion with only partial or no return migration (see the previous subsections). To put it differently, the results obtained in Sect. 5.1 are rather general. They hold if both governments base their decisions on the residence criterion and all natives return back home after graduation abroad. But they also apply independently from the return migration rate if both governments act according to the natives' principle.

\section{Conclusion}

We have examined competition in fee-financed quality levels of higher education. The mobility of students affects educational quality in regions in a very different way depending on the probability of return migration. In the extreme case in which all foreign students return to their home region, quality levels are differentiated optimally. Hence, opening up borders for mobile students results in a clear-cut overall welfare gain since the various ability types of students are matched more appropriately to the different quality levels than in a closed economy with just one quality level for all ability types.

However, in the more relevant case in which some foreign students stay in the region where they have been educated the differentiation of quality levels is less than optimal. The reason is that both regions compete to attract foreign students. In particular, at the optimally differentiated levels, the region with the highest quality level 
has an incentive to lower its level to attract the best students of the other region, which is harmful for its own students. Similarly under some conditions, the region with the lowest quality level has an incentive to raise its level above the optimal one which reduces the lifetime income of its home students. Furthermore, if the probability of return migration is sufficiently low, regions do not differentiate quality at all and the symmetric educational quality level is inefficiently high.

Our paper thus provides an important extension to the literature which so far has mostly focused on tax financing of higher education. Furthermore, our analysis confirms an important insight of Justman and Thisse (2000). They showed that their underinvestment result critically depends on the government's objective of residential welfare. If in contrast governments take into account the welfare of native-born highly educated individuals, this may lead to overinvestment. In the line of Justman and Thisse (2000), we can interpret our results such that efficiency outcomes of higher education systems as a result of increasing human capital mobility depend strongly on the underlying objectives of governments.

We consider our analysis as a first step toward studying an important and growing phenomenon: student and graduate mobility and its effects on the quality level of higher education with private funding. There are several ways to extend the analysis. Our paper focuses on quality competition with symmetric regions. One extension could be the introduction of heterogeneity across regions. ${ }^{16}$ One could distinguish small and large regions by incorporating cost functions with differing fixed cost components, with the smaller region having a higher fixed cost in setting up higher education. Another type of heterogeneity across regions could stem from differences in their school sectors. An improvement in school education enlarges the range of abilities. In terms of our model, this would mean that regions differ in their top ability type of students. This presumably modifies the outcome of competition for students.

Furthermore, we have assumed that the probability of return migration is exogenous and independent of the educational quality level. This might not be the case; the probability of return might be decreasing in the educational level. (This might apply mostly to countries with different degrees of development and opportunities for highly educated workers.) The effect on the analysis is ambiguous. Consider for example Proposition 3, according to which optimally differentiated educational quality levels do not constitute an equilibrium. This result is still true when the probability of return migration negatively depends on the educational level, but the incentives for competing for the marginal students are altered. For the region with the lowest quality level, increasing this level brings a double benefit as it increases both the number of students and the probability of the foreign ones to stay. For the region with the highest quality level, decreasing this level attracts higher ability types of students from the other region but increases their probability of return. If the second effect is large enough, the region with the highest quality level may want to increase the quality level. In that case, both regions have an incentive to increase

\footnotetext{
16 Note, however, that even in this symmetric setting, we have identified instances where asymmetric equilibria realize.
} 
the education levels. A more detailed analysis is needed to study the overall equilibrium effects. We leave those extensions for future research.

Acknowledgements Open Access funding provided by Projekt DEAL. The authors thank the editor and a referee for helpful comments.

\section{Compliance with ethical standards}

Conflict of interest The authors declare that they have no conflict of interest.

Open Access This article is licensed under a Creative Commons Attribution 4.0 International License, which permits use, sharing, adaptation, distribution and reproduction in any medium or format, as long as you give appropriate credit to the original author(s) and the source, provide a link to the Creative Commons licence, and indicate if changes were made. The images or other third party material in this article are included in the article's Creative Commons licence, unless indicated otherwise in a credit line to the material. If material is not included in the article's Creative Commons licence and your intended use is not permitted by statutory regulation or exceeds the permitted use, you will need to obtain permission directly from the copyright holder. To view a copy of this licence, visit http://creativecommons.org/licen ses/by/4.0/.

\section{Appendix 1: Proofs}

Proof of Lemma 2 Let $e^{A}>e^{B}$. We have

$$
\begin{aligned}
T W\left(e^{A}, e^{B}\right)= & w_{\mathrm{s}}\left[2\left(\bar{y}-y^{A B}\right) \frac{\bar{y}+y^{A B}}{2} e^{A}+2\left(y^{A B}-y^{u}\right) \frac{y^{A B}+y^{u}}{2} e^{B}\right] \\
& +4 w_{\mathrm{u}} y^{u}-2\left(\bar{y}-y^{A B}\right) c\left(e^{A}\right)-2\left(y^{A B}-y^{u}\right) c\left(e^{B}\right) .
\end{aligned}
$$

The derivative of this expression with respect to $e^{A}$ is the sum of a direct effect on the current students $\left(\bar{y}-y^{A B}\right)\left[w_{\mathrm{s}}\left(\bar{y}+y^{A B}\right)-2 c^{\prime}\left(e^{A}\right)\right]$ and an indirect effect due to the change in the threshold $y^{A B}$. The indirect effect is null because there is no distortion in individuals' choices. This can be checked as follows. The indirect effect is equal to

$$
2 \frac{\partial y^{A B}}{\partial e}\left[-w_{\mathrm{s}} y^{A B} e^{A}+c\left(e^{A}\right)+w_{\mathrm{s}} y^{A B} e^{B}-c\left(e^{B}\right)\right] .
$$

The term in brackets is null because individuals split voluntarily across regions according to $w_{\mathrm{s}} y^{A B} e^{A}-c\left(e^{A}\right)=w_{\mathrm{s}} y^{A B} e^{B}-c\left(e^{B}\right)$ whatever the quality levels are. We are left with the direct effect. Taking the limit when $e^{A}$ tends to $e^{B}=e, y^{A B}$ tends to $y^{\lim }=\frac{c^{\prime}(e)}{w_{\mathrm{s}}}$. Thus, the direct effect $\left(\bar{y}-y^{A B}\right)\left[w_{\mathrm{s}}\left(\bar{y}+y^{A B}\right)-2 c^{\prime}\left(e^{A}\right)\right]$ tends to $w_{\mathrm{s}}\left(\bar{y}-\frac{c_{\mathrm{s}}^{\prime}(e)}{w_{\mathrm{s}}}\right)^{2}$, which is equal to $\lim _{e^{A} \rightarrow e^{+}} \frac{\partial T W}{\partial e^{A}}\left(e^{A}, e\right)$, as given in (37).

Consider now the derivative of $T W$ with respect to $e^{B}$ with $e^{B}<e^{A}$. It is the sum of a direct effect $\left(y^{A B}-y^{u}\right)\left[w_{\mathrm{s}}\left(y^{A B}+y^{u}\right)-2 c^{\prime}\left(e^{B}\right)\right]$ and an indirect effect due to the changes in the thresholds $y^{A B}$ and $y^{u}$. The indirect effect due to the change in $y^{A B}$ vanishes by the same argument as above. Similarly, the marginal indirect effect due 
to the change in $y^{u}$ is null because there is no distortion in individuals' choices. This is checked since the indirect effect is

$$
\frac{\partial y^{u}}{\partial e}\left[-w_{\mathrm{s}} y^{u} e^{B}+c\left(e^{B}\right)+2 w_{\mathrm{u}}\right]
$$

and the term in square brackets is null. Again, we are left with the direct effect only. Taking the limit as $e^{B}$ tends to $e^{A}=e$, the direct effect $\left(y^{A B}-y^{u}\right)\left[w_{\mathrm{s}}\left(y^{A B}+y^{u}\right)-2 c^{\prime}\left(e^{B}\right)\right]$ tends to $\left(y^{\lim }-y^{u}\right)\left(w_{\mathrm{s}}\left(y^{\lim }+y^{u}\right)-2 c^{\prime}(e)\right)$ and using $w_{\mathrm{s}} y^{\text {lim }}=c^{\prime}(e)$ gives $\lim _{e^{B} \rightarrow e^{-}} \frac{\partial T W}{\partial e^{B}}\left(e, e^{B}\right)=-w_{\mathrm{s}}\left(\frac{c^{\prime}(e)}{w_{\mathrm{s}}}-y^{u}\right)^{2}$ as given in (37).

Furthermore, setting the direct effects equal to zero a comparison with the optimality conditions in (19) shows that maximal total welfare is achieved with $e^{A}=\bar{e}^{*}$ and $e^{B}=\underline{e}^{*}$.

Proof of Proposition 1 Let $e^{A}>e^{B}$. Region $A$ chooses its quality level by maximizing the natives' welfare from (38). Differentiating the concave welfare function with respect to $e^{A}$ yields the first-order condition:

$$
\begin{aligned}
\frac{\partial W_{\mid \pi=1}^{A}}{\partial e^{A}}= & \left(\bar{y}-y^{A B}\right)\left[w_{\mathrm{s}} \frac{\bar{y}+y^{A B}}{2}-c^{\prime}\left(e^{A}\right)\right] \\
& +\frac{\partial y^{A B}}{\partial e^{A}}\left[w_{\mathrm{s}} e^{B} y^{A B}-c\left(e^{B}\right)-\left(w_{\mathrm{s}} e^{A} y^{A B}-c\left(e^{A}\right)\right)\right] \\
= & 0 .
\end{aligned}
$$

From Lemma 1, we know that students partition themselves optimally across both regions so that $w_{\mathrm{s}} e^{B} y^{A B}-c\left(e^{B}\right)=w_{\mathrm{s}} e^{A} y^{A B}-c\left(e^{A}\right)$. Hence, region A's quality level is determined by the condition $w_{\mathrm{s}} \frac{\bar{y}+y^{A B}}{2}=c^{\prime}\left(e^{A}\right)$ which is the optimal quality level according to (19). The welfare maximum of region $B$ is given by

$$
\begin{aligned}
\frac{\partial W_{\mid \pi=1}^{B}}{\partial e^{B}}= & \left(y^{A B}-y^{u}\right)\left[w_{\mathrm{s}} \frac{y^{A B}+y^{u}}{2}-c^{\prime}\left(e^{B}\right)\right] \\
& +\frac{\partial y^{A B}}{\partial e^{B}}\left[w_{\mathrm{s}} e^{B} y^{A B}-c\left(e^{B}\right)-\left(w_{\mathrm{s}} e^{A} y^{A B}-c\left(e^{A}\right)\right)\right] \\
& -\frac{\partial y^{u}}{\partial e^{B}}\left[w_{\mathrm{s}} e^{B} y^{u}-c\left(e^{B}\right)-2 w_{\mathrm{u}}\right] \\
= & 0 .
\end{aligned}
$$

From Lemma 1 again, students split optimally across regions according to (23) and the lower ability types of individuals divide optimally in remaining unskilled and receiving higher education in region $\mathrm{B}: w_{\mathrm{s}} e^{B} y^{u}-c\left(e^{B}\right)=2 w_{\mathrm{u}}$. Hence, the educational quality level chosen by region $B$ is given by $w_{\mathrm{s}} \frac{y^{A B}+y^{u}}{2}=c^{\prime}\left(e^{B}\right)$ which is optimal according to condition (19).

Since the voluntary partition of both students between regions and unskilled and skilled labor is optimal whatever the quality level is, regions choose always the optimally differentiated quality levels and the Nash equilibrium is unique. 
Proof of Lemma 3 The sum of the welfare in the two regions associated with the two quality levels, $e^{A}, e^{B}$, is given by the total welfare function

$$
\begin{aligned}
T W\left(e^{A}, e^{B}\right)= & {\left[W_{\mid \pi=0}^{A}+W_{\mid \pi=0}^{B}\right]\left(e^{A}, e^{B}\right) } \\
= & w_{\mathrm{s}}\left[2\left(\bar{y}-y^{A B}\right) \frac{\bar{y}+y^{A B}}{2} e^{A}+2\left(y^{A B}-y^{u}\right) \frac{y^{A B}+y^{u}}{2} e^{B}\right] \\
& +4 w_{\mathrm{u}} y^{u}-2\left(\bar{y}-y^{A B}\right) c\left(e^{A}\right)-2\left(y^{A B}-y^{u}\right) c\left(e^{B}\right) .
\end{aligned}
$$

$T W$ is continuous. Taking the limit as $e^{A}$ and $e^{B}$ tend to $e$, we obtain

$$
\lim _{e^{A} \rightarrow e^{-}, e^{B} \rightarrow e^{+}} W_{\mid \pi=0}^{A}\left(e^{A}, e^{B}\right)+\lim _{e^{A} \rightarrow e^{-}, e^{B} \rightarrow e^{+}} W_{\mid \pi=0}^{B}\left(e^{A}, e^{B}\right)=T W(e, e) .
$$

By symmetry $W_{\mid \pi=0}^{A}\left(e^{A}, e^{B}\right)=W_{\mid \pi=0}^{B}\left(e^{B}, e^{A}\right)$ and $2 W_{\mid \pi=0}^{A}(e, e)=2 W_{\mid \pi=0}^{B}(e, e)=T W(e, e)$. This gives

$$
\lim _{e^{A} \rightarrow e^{-}, e^{B} \rightarrow e^{+}} W_{\mid \pi=0}^{B}\left(e^{A}, e^{B}\right)=\lim _{e^{A} \rightarrow e^{+}, e^{B} \rightarrow e^{-}} W_{\mid \pi=0}^{A}\left(e^{A}, e^{B}\right) .
$$

Plugging (52) into (51)

$$
\lim _{e^{A} \rightarrow e^{-}, e^{B} \rightarrow e^{+}} W_{\mid \pi=0}^{A}\left(e^{A}, e^{B}\right)+\lim _{e^{A} \rightarrow e^{+}, e^{B} \rightarrow e^{-}} W_{\mid \pi=0}^{A}\left(e^{A}, e^{B}\right)=T W(e, e) .
$$

Taking $e^{B}=e$ in the above equation gives Eq. (45).

Since the jumps are in the same direction, jumps must be null at a symmetric equilibrium: If the jump is positive at $(e, e)$, a region benefits by proposing a level higher than $e$ and if it is negative it benefits by proposing a smaller one.

Proof of Proposition 2 Let us determine the best response of a region, say $A$, to the quality level chosen by the other region. Given $e^{B}=e$, consider $W^{A}\left(e^{A}, e\right)$ as a function of $e^{A}$. We need to distinguish three cases depending on $e^{A}$ being smaller than, equal to, or larger than $e$. Also, we want both regions to have students, which requires $y^{u}<y^{A B}<\bar{y}$. The first inequality holds true if $\frac{c^{\prime}(e)}{w_{\mathrm{s}}}>\frac{2 w_{\mathrm{u}}+c(e)}{w_{\mathrm{s}} e}$ (cf. (23) and (25)), i.e., for $c(e)=e^{2}$ if $e^{2}>2 w_{\mathrm{u}}$.

(1) As long as $e^{A}<e^{B}=e$, region $A$ attracts students with low ability, i.e., between $y^{u}\left(e^{A}\right)$ and $y^{A B}$. The derivative is (cf. (48) where the roles of $A$ and $B$ are exchanged and where we use $\left.\left[-y^{u} e^{A} w_{\mathrm{s}}+w_{\mathrm{u}}+c\left(e^{A}\right)\right]=-w_{\mathrm{u}}\right)$

$$
\begin{aligned}
\frac{\partial W^{A}}{\partial e^{A}}= & 2\left(y^{A B}-y^{u}\right)\left[w_{\mathrm{s}} \frac{y^{A B}+y^{u}}{2}-c^{\prime}\left(e^{A}\right)\right] \\
& +2\left[y^{A B} e^{A} w_{\mathrm{s}}-c\left(e^{A}\right)\right] \frac{\partial y^{A B}}{\partial e^{A}}-2 w_{\mathrm{u}} \frac{\partial y^{u}}{\partial e^{A}}
\end{aligned}
$$

for $e^{A}<e^{B}$.

Check that with a quadratic cost function, the derivative is linear in $e^{A}$ and increasing: $A$ prefers to be as close as possible to $e$ in this zone. Therefore, 
if the region prefers to be the one with the lowest level its best response is 'almost' to match the other region's level $e$. Furthermore, this implies that there is no asymmetric equilibrium since the region with the lower educational quality level increases its welfare by increasing its level.

(2) Consider the zone with $e^{A}>e$. We have

$$
\frac{\partial W^{A}}{\partial e^{A}}=2\left(\bar{y}-y^{A B}\right)\left[w_{\mathrm{s}} \frac{\bar{y}+y^{A B}}{2}-c^{\prime}\left(e^{A}\right)\right]-2\left[y^{A B} e^{A} w_{\mathrm{s}}-c\left(e^{A}\right)\right] \frac{\partial y^{A B}}{\partial e^{A}}
$$

for $e^{A}>e^{B}$.

The derivative is null at an 'interior' best response, one that is indeed above $e$. Check that with a quadratic cost function the best response is decreasing with $e$. (Write $\frac{\partial W^{A}}{\partial e^{A}}=0$ and impose the solution to be larger than $e$.) The minimum ability level of those who decide to study, $y^{u}$, depends only on the minimum educational quality level. Thus, it is continuous and stays constant for $e^{A}$ larger than $e$.

(3) We need to examine carefully the behavior when $e^{A}$ is close to $e$ because of discontinuities. We know that the limit of $y^{A B}$ when $e^{A}$ tends to $e$ is $y^{\lim }(e)$ given by (33): Let us denote by $D(e)$ the jump on $A$ 's welfare as $e^{A}$ approaches $e=e^{B}$ from above: $D(e)=\lim _{e^{A} \rightarrow e^{+}} W_{\mid \pi=0}^{A}\left(e^{A}, e\right)-\frac{1}{2} T W(e, e)$. Since $W_{\mid \pi=0}^{A}+W_{\mid \pi=0}^{B}=T W$, we have

$$
\left[W_{\mid \pi=0}^{A}-\frac{1}{2} T W\right]\left(e^{A}, e^{B}\right)=\frac{1}{2}\left[W_{\mid \pi=0}^{A}-W_{\mid \pi=0}^{B}\right]\left(e^{A}, e^{B}\right) .
$$

From (40) and (41), the value $\frac{1}{2}\left[W_{\mid \pi=0}^{A}-W_{\mid \pi=0}^{B}\right]\left(e^{A}, e^{B}\right)$ for $e^{A}>e^{B}$ is

$$
\left(\bar{y}-y^{A B}\right)\left[w_{\mathrm{s}} \frac{\bar{y}+y^{A B}}{2} e^{A}-c\left(e^{A}\right)\right]-\left(y^{A B}-y^{u}\right)\left[w_{\mathrm{s}} \frac{y^{A B}+y^{u}}{2} e^{B}-c\left(e^{B}\right)\right]
$$

where $y^{A B}$ is a function of $e^{A}$ and $e^{B}$ and $y^{u}$ of $e^{B} . D(e)$ is obtained by taking the limit when $e^{A}$ tends to $e=e^{B}$ from above. Since $y^{A B}$ tends to $y^{\lim }(e)$, and $y^{u}$ is equal to $y^{u}(e)=\frac{2 w_{u}+c(e)}{w_{s} e}$, we obtain

$$
\begin{aligned}
D(e)= & \left(\bar{y}-y^{\lim }(e)\right)\left[w_{\mathrm{s}} \frac{\bar{y}+y^{\lim }(e)}{2} e-c(e)\right] \\
& -\left(y^{l i m}(e)-y^{u}(e)\right)\left[w_{\mathrm{s}} \frac{y^{l i m}(e)+y^{u}(e)}{2} e-c(e)\right] .
\end{aligned}
$$

For $c(e)=\alpha e^{2}, w_{s} y^{l i m}(e)=2 \alpha e$ and hence $w_{\mathrm{s}} \frac{y^{l i m}}{2} e-c(e)=0$. Thus,

$$
D(e)=\frac{w_{s}}{2} e\left[\left(\bar{y}-y^{l i m}(e)\right) \bar{y}-\left(y^{\lim }(e)-y^{u}(e)\right) y^{u}(e)\right]
$$

$D(e)$ is of the same sign as the term in brackets. This term is positive at $e^{*}$ (as we know from the text or directly using that $\left(\bar{y}-y^{\lim }(e)\right)=\left(y^{\lim }(e)-y^{u}(e)\right)$ at $\left.e^{*}\right)$. It is negative for $e$ large enough so that $y^{\lim }(e)$ equals $\bar{y}$. Furthermore, the term decreases with $e$ because $y^{\lim }(e)$ increases, $\left(y^{\lim }-y^{u}\right)=\frac{1}{w_{s}}\left(\alpha e-\frac{w_{u}}{e}\right)$ 
increases, and $y^{u}(e)=\frac{2 w_{u}+\alpha e^{2}}{w_{s} e}$ increases. Hence, there is a unique value $\hat{e}$ for which $D(\widehat{e})=0$, and furthermore this value is larger than $e^{*}$.

At $\hat{e}$ level, the net benefit from educating high-ability students, those with ability larger than $y^{A B}$, is exactly equal to the net benefit from educating low-ability students, those with ability between $y^{A B}$ and $y^{u}$.

Consider a value $e$ larger than $\hat{e}$. No region benefits by improving the quality level. Each benefits from choosing an educational quality level just below the other one. Similarly, for a value $e$ smaller than $\hat{e}$, a region benefits by improving the quality level above $e$. We are left with $(\hat{e}, \hat{e})$ as the only possibility for an equilibrium in pure strategies. We determine conditions under which $(\hat{e}, \hat{e})$ is indeed an equilibrium. Take $e^{B}=\widehat{e}$, and consider the welfare of $A$, for example. (By symmetry the same argument works for $B$.) A's welfare is continuous at $\hat{e}$. Furthermore, it increases for $e^{A}<\hat{e}$. Hence, if $A$ 's welfare decreases for $e^{A}>\hat{e}$, $\widehat{e}$ is indeed a best response to $e^{B}=\widehat{e}$ and $(\widehat{e}, \hat{e})$ is an equilibrium. Recall that a region's welfare is concave when it has the largest quality level. Therefore, $A$ 's welfare decreases for $e>\hat{e}$ if and only if the 'right' derivative $\lim _{e^{A} \rightarrow>e} \frac{\partial W^{A}}{\partial e^{A}}$ is negative (since, in that case, the concavity of $W^{A}$ for $e>\hat{e}$ implies that $\frac{\partial W^{A}}{\partial e^{A}}$ is negative for $e>\hat{e}$ and, hence, $A$ 's welfare decreases).

Proof of Proposition 3 Regions maximize welfare

$$
W^{I}\left(e^{A}, e^{B}\right)=(1-\pi) W_{\mid \pi=0}^{I}\left(e^{A}, e^{B}\right)+\pi W_{\mid \pi=1}^{I}\left(e^{A}, e^{B}\right) I=A, B .
$$

We evaluate the partial derivatives of the welfare functions $W^{I}$ at $\left(\bar{e}^{*}, e^{*}\right)$ that is assuming that regions provide the optimally differentiated quality levels $e^{\bar{A}}=\bar{e}^{*}$ and $e^{B}=\underline{e}^{*}$. From (29), these partial derivatives are a combination of the partial derivatives of $W_{\mid \pi=0}^{I}$ and $W_{\mid \pi=1}^{I}, I=A, B$.

The derivatives $\frac{\partial W_{\mid \pi=1}^{A}}{\partial e^{A}}\left(\bar{e}^{*}, \underline{e}^{*}\right)$ and $\frac{\partial W_{\mid \pi=1}^{B}}{\partial e^{B}}\left(\bar{e}^{*}, \underline{e}^{*}\right)$ are null because optimal differentiation levels form a Nash equilibrium (Proposition 1). Thus,

$$
\frac{\partial W^{A}}{\partial e^{A}}\left(\bar{e}^{*}, \underline{e}^{*}\right)=(1-\pi) \frac{\partial W_{\mid \pi=0}^{A}}{\partial e^{A}}\left(\bar{e}^{*}, \underline{e}^{*}\right)
$$

and similarly for $B$. Expressions (47) and (48) give

$$
\begin{aligned}
\frac{\partial W_{\mid \pi=0}^{A}}{\partial e^{A}}\left(e^{A}, e^{B}\right)= & 2\left(\bar{y}-y^{A B}\right)\left[w_{\mathrm{s}} \frac{\bar{y}+y^{A B}}{2}-c^{\prime}\left(e^{A}\right)\right]+2\left[y^{A B} e^{A} w_{\mathrm{s}}-c\left(e^{A}\right)\right]\left(-\frac{\partial y^{A B}}{\partial e^{A}}\right) \\
\frac{\partial W_{\mid \pi=0}^{B}}{\partial e^{B}}\left(e^{A}, e^{B}\right)= & 2\left(y^{A B}-y^{u}\right)\left[w_{\mathrm{s}} \frac{y^{A B}+y^{u}}{2}-c^{\prime}\left(e^{B}\right)\right]+2\left[y^{A B} e^{B} w_{\mathrm{s}}-c\left(e^{B}\right)\right] \frac{\partial y^{A B}}{\partial e^{B}} \\
& +2\left[y^{u} e^{B} w_{\mathrm{s}}-w_{\mathrm{u}}-c\left(e^{B}\right)\right]\left(-\frac{\partial y^{u}}{\partial e^{B}}\right) .
\end{aligned}
$$


At $\left(\bar{e}^{*}, \underline{e}^{*}\right)$, the first terms in squared brackets in (47) and (48), which represent the efficiency gains, are zero.

The second term in (47) is negative since $\left[y^{A B} e^{A} w_{\mathrm{s}}-c\left(e^{A}\right)\right]>0$ and

$$
\frac{\partial y^{A B}}{\partial e^{A}}=\frac{c^{\prime}\left(e^{A}\right)-w_{\mathrm{s}} y^{A B}}{w_{\mathrm{s}}\left(e^{A}-e^{B}\right)}>0 .
$$

Hence, region $A$ 's welfare increases if $e^{A}$ decreases below $\bar{e}^{*}$.

The second term in (48) is positive since $\left[y^{A B} e^{B} w_{\mathrm{s}}-c\left(e^{B}\right)\right]>0$ and

$$
\frac{\partial y^{A B}}{\partial e^{B}}=\frac{w_{\mathrm{s}} y^{A B}-c^{\prime}\left(e^{B}\right)}{w_{\mathrm{s}}\left(e^{A}-e^{B}\right)}>0 .
$$

The third term in (48) is negative since $\left[-y^{u} e^{B} w_{\mathrm{s}}+w_{\mathrm{u}}+c\left(e^{B}\right)\right]=-w_{\mathrm{u}}$ by definition of $y^{u}$ (see (25)). And at $e^{B}=\underline{e}^{*}$ we get

$$
\left.\frac{\partial y^{u}}{\partial e^{B}}\right|_{e^{B}=e^{*}}=\frac{c^{\prime}\left(e^{B}\right)-w_{\mathrm{s}} y^{u}}{w_{\mathrm{s}} e^{B}}>0
$$

because $c^{\prime}\left(e^{B}\right)=w_{\mathrm{s}} \frac{y^{A B}+y^{u}}{2}>w_{\mathrm{s}} y^{u}$. A quality level $e^{B}$ higher than $\underline{e}^{*}$ is welfare improving for region $B$ if and only if

$$
\left[\left[y^{A B} e^{B} w_{\mathrm{s}}-c\left(e^{B}\right)\right] \frac{\partial y^{A B}}{\partial e^{B}}-w_{\mathrm{u}} \frac{\partial y^{u}}{\partial e^{B}}\right]_{e^{B}=\underline{e}^{*}}>0 .
$$

We compare both terms factorwise. First, we have $y^{A B} e^{B} w_{\mathrm{s}}-c\left(e^{B}\right)>y^{u} e^{B} w_{\mathrm{s}}$ $-c\left(e^{B}\right)=2 w_{\mathrm{u}}>w_{\mathrm{u}}$. Second, we show that $\frac{\partial y^{A B}}{\partial e^{B}}>\frac{\partial y^{u}}{\partial e^{B}}$ if $e^{B}>\frac{e^{A}}{2}$ at the optimal differentiation. For the following calculation, we use that the optimally differentiated quality level $e^{B}$ satisfies $c^{\prime}\left(e^{B}\right)=w_{s} \frac{y^{A B}+y^{u}}{2}$

$$
\begin{aligned}
& \frac{w_{s} y^{A B}-c^{\prime}\left(e^{B}\right)}{w_{s}\left(e^{A}-e^{B}\right)}-\frac{c^{\prime}\left(e^{B}\right)-w_{s} y^{u}}{w_{s} e^{B}} \\
= & \frac{1}{\left(e^{A}-e^{B}\right) w_{s} e^{B}}\left[\left(e^{B}-\frac{e^{A}}{2}\right) w_{s}\left(y^{A B}-y^{u}\right)\right] .
\end{aligned}
$$

If $e^{B}>\frac{e^{A}}{2}$, we have $\frac{\partial y^{A B}}{\partial e^{B}}>\frac{\partial y^{u}}{\partial e^{B}}$ which proves the proposition.

Proof of Proposition 4 Consider the unique candidate for a symmetric equilibrium, $(\hat{e}, \hat{e})$. By definition of $\hat{e}$, a region's objective is continuous at $\hat{e}$ with respect to its quality level. However, there is typically a kink, that is, the right and left derivatives do not coincide. Take $e^{B}=\widehat{e}$, and consider welfare of $A$ for example. (By symmetry, the same argument works for $B$.) An equilibrium is obtained at $(\hat{e}, \widehat{e})$ only if the left derivative is nonnegative and the right one is nonpositive, i.e.,

$$
\lim _{e^{A} \rightarrow \widehat{e}^{-}} \frac{\partial W_{\mid \pi=1}^{A}}{\partial e^{A}}\left(e^{A}, \widehat{e}\right) \geq 0 \text { and } \lim _{e^{A} \rightarrow \widehat{e}^{+}} \frac{\partial W_{\mid \pi=1}^{A}}{\partial e^{A}}\left(e^{A}, \widehat{e}\right) \leq 0 .
$$


Assume there is scope for differentiation at $\hat{e}$. Then, conditions (58) are never satisfied at $\pi=1$. More precisely, since $W_{\mid \pi=1}^{A}\left(e^{A}, e^{B}\right)$ is half of total welfare $T W\left(e^{A}, e^{B}\right)$, we know from Lemma 2 that

$$
\lim _{e^{A} \rightarrow \widehat{e}^{-}} \frac{\partial W_{\mid \pi=1}^{A}}{\partial e^{A}}\left(e^{A}, \widehat{e}\right) \leq 0, \text { and } \lim _{e^{A} \rightarrow \widehat{e}^{+}} \frac{\partial W_{\mid \pi=1}^{A}}{\partial e^{A}}\left(e^{A}, \widehat{e}\right) \geq 0 .
$$

Consider now a return probability $\pi<1$. A region's objective criterion is a combination of the criterion that obtains in the two extreme cases. Thus, we have for $e^{A} \neq \hat{e}$

$$
\frac{\partial W^{A}}{\partial e^{A}}\left(e^{A}, \hat{e}\right)=(1-\pi) \frac{\partial W_{\mid \pi=0}^{A}}{\partial e^{A}}\left(e^{A}, \hat{e}\right)+\pi \frac{\partial W_{\mid \pi=1}^{A}}{\partial e^{A}}\left(e^{A}, \widehat{e}\right)
$$

and the same convex combination applies at the limit when $e^{A}$ tends to $\hat{e}$ alternatively for $e^{A}>\hat{e}$ and $e^{A}<\hat{e}$. Assume that the first inequality in (58) holds for $\pi<1$. Since $\lim _{e^{A} \rightarrow \widehat{e}^{-}} \frac{\partial W_{\mid \pi=1}^{A}}{\partial e^{A}}\left(e^{A}, \widehat{e}\right) \leq 0$, it must be that $\lim _{e^{A} \rightarrow \widehat{e}^{-}} \frac{\partial W_{\mid \pi=0}^{A}}{\partial e^{A}}\left(e^{A}, \widehat{e}\right)$ is positive. Decreasing $\pi$ increases the weight on this positive term and decreases the weight on the negative one: Surely $\lim _{e^{A} \rightarrow \hat{e}^{-}} \frac{\partial W_{\mid \pi=1}^{A}}{\partial e^{A}}\left(e^{A}, \hat{e}\right)>0$ for smaller $\pi$. Similarly, if the second inequality in (58) holds for $\pi<1$, it holds for any smaller value for $\pi$. This proves Proposition 4.

\section{Appendix 2: Illustrations}

\section{Full return migration $(\pi=1)$}

This section illustrates the response functions for $\pi=1$ for the following specifications: The cost function is quadratic and given by $c(e)=(e)^{2}$. The skilled and unskilled wage rates are given by $w_{s}=2$ and $w_{\mathrm{u}}=1$, respectively. The maximal ability level is set at $\bar{y}=10$. For $e^{A} \in[0 ; 10]$ and $e^{B} \in[0 ; 10]$, the restriction holds that $\bar{y} \geq y^{A B}$. Figure 3 displays the response functions and the Nash equilibrium.

The response function of one region is first increasing in the quality level of the other region. The reason is the following. Starting with a low educational quality level in, let us say, region $B$, all the upper ability types of students in the range $\left[y^{A B}, \bar{y}\right]$ study in region $A$. For increasing values of the quality level in region $B$, the threshold ability $y^{A B}$ goes up. This implies that the average ability level of the more able students in region $A$ rises. In order to maximize their lifetime income, in response, region $A$ increases also its quality level. Given our reasoning above, quality levels are only determined based on efficiency considerations.

At some point where the quality level of region $B$ is high enough, the welfare gain for region $A$ of educating high-ability students becomes smaller than the welfare gain of educating low-ability students. Now, region $A$ chooses to educate low-ability types and the roles of both regions are interchanged. This is reflected by the jump downwards of the response function of region $A$ in Fig. 3. 


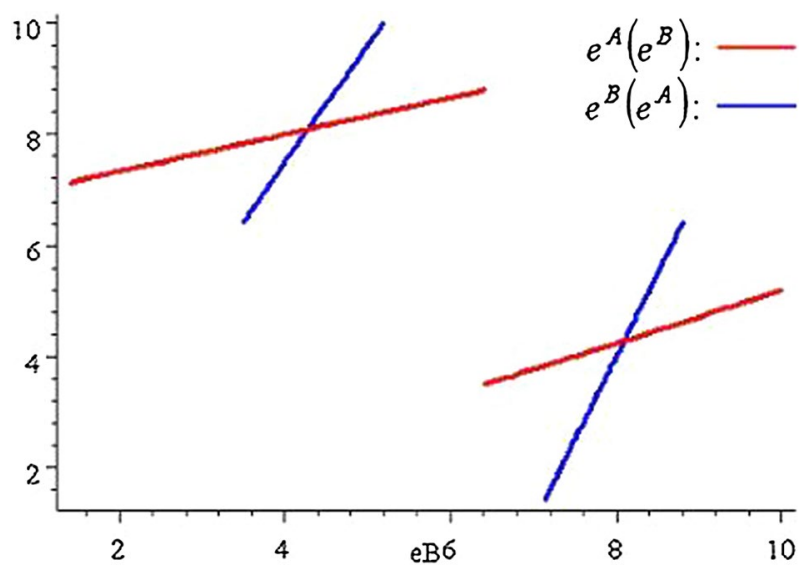

Fig. 3 Response functions in the case $\pi=1$

In the Nash equilibria, the optimal differentiation of the quality levels is achieved. This is where the response functions intersect in the figure. In our example, the optimal high and low levels of educational quality in the Nash equilibria are given by

$$
\underline{e}^{*}=4.3, \bar{e}^{*}=8.1 \text {. }
$$

\section{No return migration $(\pi=0)$}

This section illustrates the competition for students and the induced discontinuities of the welfare functions as established above. We use again the specifications (see the full-return-migration case) in particular a quadratic cost function. Calculations yield for the optimal single level $e^{*}$ and for the value $\widehat{e}$

$$
e^{*}=6.765, \hat{e}=8.285 \text {. }
$$

As expected, the quality level at the symmetric equilibrium, $\hat{e}$, is larger than the optimal level in a closed economy, $e^{*}$. In addition, $\underline{e}^{*}=4.3$ and $\bar{e}^{*}=8.1$ (see the full-return-migration case). In the following, we study the welfare of region $A$ for two quality levels of region $B, e^{B}=e^{*}$ and $e^{B}=\hat{e}$

In Fig. 4a, welfare of region $A$ is derived for given $e^{B}=e^{*}$. The welfare function is piecewise defined with a cutoff point when $A$ chooses the same level as $B$. It is concave in each domain, but because of the discontinuity when $e^{A}=e^{B}$, welfare is not overall concave in $e^{A}$. There is a jump up to the dot when $e^{A}$ reaches $e^{B}$ because $A$ and $B$ now share the students equally. The other jump, which is in the same direction and of the same magnitude as the first one by Lemma 3 , occurs when $e^{A}$ becomes larger than $e^{B}$. The roles of $A$ and $B$ are exchanged with $A$ now attracting the highability students. 


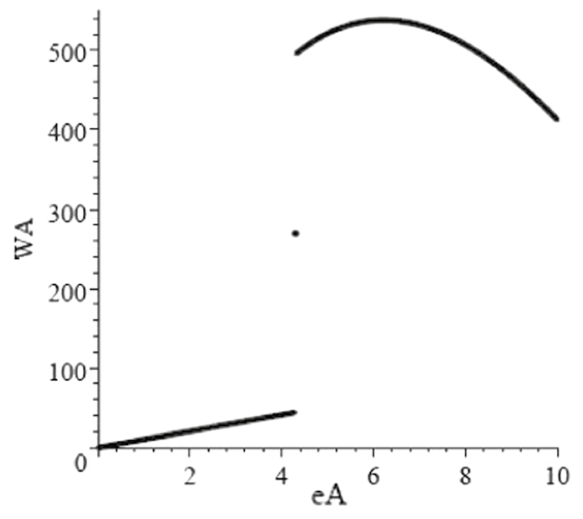

(a) For $e^{B}=\underline{e}^{*}=4.3$

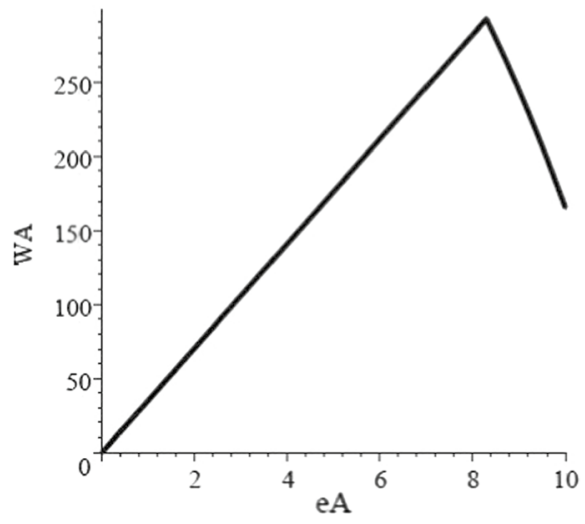

(b) For $e^{B}=\widehat{e}=8.285$

Fig. 4 Welfare of region A for $\pi=0$.

Which quality level region $A$ will choose depends on a comparison of the maximal welfare levels for each part, that is for $e^{A}$ strictly less, equal to, or strictly larger than $e^{B}=\underline{e}^{*}=4.3$. In the first part, for $e^{A}<\underline{e}^{*}$, welfare increases linearly with $e^{A}$ and the maximum is achieved by approaching the quality level $e^{*}$ from below. The maximal welfare is $\lim _{e^{A} \rightarrow \underline{e}^{*}} W^{A}\left(e^{A}<\underline{e}^{*}\right) \approx 44.05$. In the second part, reduced to a singleton, region $A$ chooses the same level as region $B, e^{A}=e^{B}=e^{*}$, and welfare is 269.5 from (42). In the third part, for $e^{A}>\underline{e}^{*}$, the welfare function is strictly concave and has a maximal value $W^{A}\left(e^{A}>\underline{e}^{*}\right)=537.8$ reached at $e^{A}=6.2$. Hence, region $A$ maximizes its welfare by choosing quality level 6.2 , which falls short of the optimally differentiated level, $6.2<\bar{e}^{*}$.

Figure $4 \mathrm{~b}$ illustrates the case $e^{B}=\widehat{e}$. Here, region $A$ 's welfare function is continuous. Region $A$ maximizes its welfare by choosing the same quality level as region $B, e^{A}=e^{B}=\widehat{e}$.

The best response functions of both regions are depicted in Fig. 5. The intuition for the shape of the response function of region $A$ (and vice versa for region $B$ ) is the following. Starting with a low quality level in region $B$, an increase in this level attracts high-ability students from region $A$. As a response, region $A$ decreases its quality level in order to regain these lost students. The essential point in the case of $\pi=0$ is that the students do not come back once they have decided to study in a foreign region. Thus, regions compete for the students by choosing their quality levels appropriately. If region $A$ 's quality level gets close to the level of region $B$, the number of students in both regions is nearly the same as with symmetric levels, but the composition of abilities depends on which level is the highest. Region $A$ starts to keep its educational quality level slightly higher than region $B$ in order to keep the high-ability students. Hence, the response function increases with the level in the other region. At some point, the welfare gain for $A$ of educating high-ability students is equal to the welfare gain of educating the low-ability types. This point $(\hat{e}, \hat{e})$ where the quality levels 


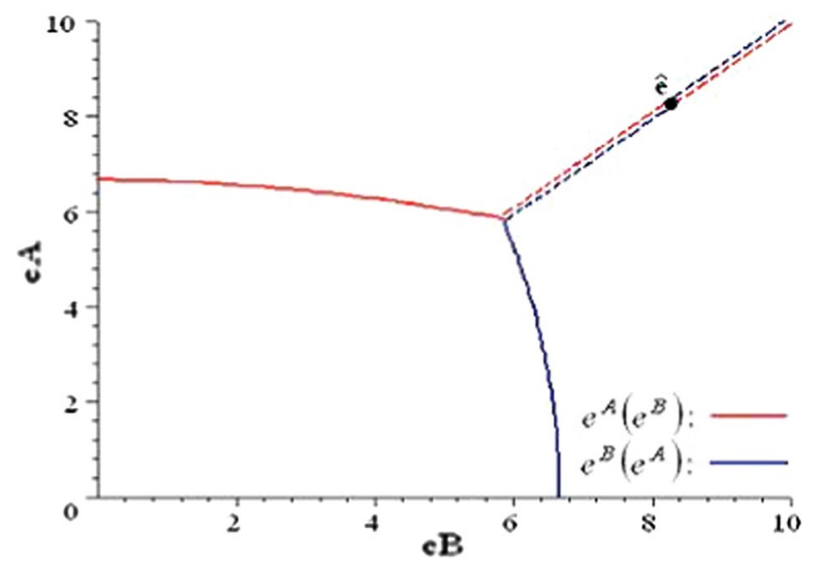

Fig. 5 Response functions in the case of $\pi=0$.

are symmetric-marked by a black dot in the figure-is the only one where the welfare functions in both regions are well defined and therefore the only candidate for a Nash equilibrium. If region $B$ increases its quality level further, region $A$ benefits from educating the lower ability students by keeping its quality level slightly below the level of region $B$.

\section{Intermediate return migration $(0<\pi<1)$}

We illustrate for $e^{B}=\widehat{e}=8.285$ that the welfare function of region $A$ is continuous independent of all return probabilities in the range of $0 \leq \pi<1$. See Fig. 6 for $\pi=2 / 3,0.9$ and Fig. $4 \mathrm{~b}$ for $\pi=0$. Only in the two cases of $\pi=0$ and $\pi=2 / 3, \hat{e}$

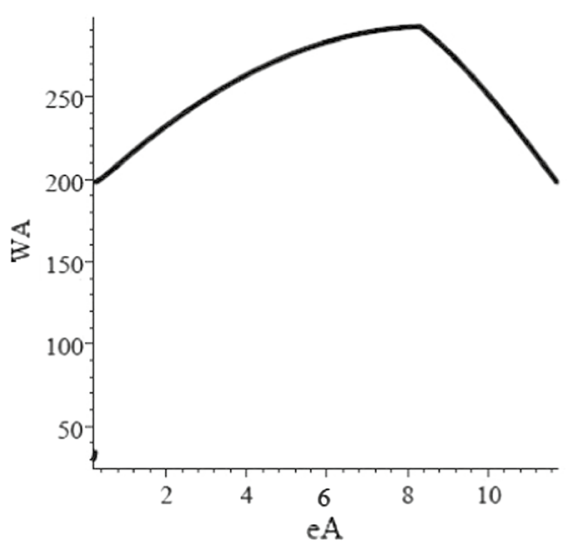

(a) For $\pi=2 / 3$

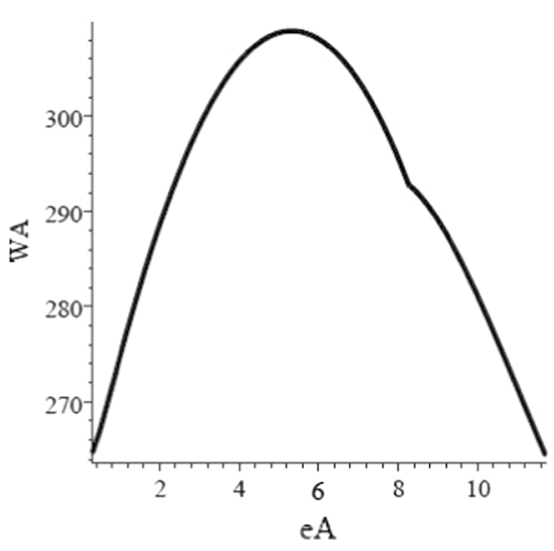

(b) For $\pi=0.9$

Fig. 6 Welfare of region $\mathrm{A}$ at $e^{B}=\widehat{e}=8.285$ 
yields a symmetric equilibrium. As expected, the return probability $\pi$ must be small enough to guarantee its existence.

\section{References}

Blackorby, C., Bossert, W., \& Donaldson, D. (2009). Population ethics. In P. Anand, P. Pattanaik, \& C. Puppe (Eds.), Handbook of rational and social choice (pp. 483-500). Oxford: Oxford University Press.

Chaloff, J., \& Lemaitre, G. (2009). Managing highly-skilled labour migration: A comparative analysis of migration policies and challenges in OECD Countries. OECD Social, Employment and Migration Working Paper 79.

Coniglio, N. D., \& Prota, F. (2008). Human capital accumulation and migration in a peripheral EU region: The case of basilicata. Papers in Regional Science, 87, 77-95.

Delpierre, M., \& Verheyden, B. (2014). Student and worker mobility under university and government competition. Journal of Public Economics, 110, 26-41.

Del Rey, E. (2001). Economic integration and public provision of education. Empirica, 28, 203-218.

Demange, G., Fenge, R., \& Uebelmesser, S. (2014). Financing higher education in a mobile world. Journal of Public Economic Theory, 16, 343-371.

Ehrenberg, R. G., \& Smith, R. S. (1993). Modern labor economics: Theory and public policy. New York: Harper Collins.

Gabszewicz, J., \& Thisse, J.-F. (1979). Price competition, quality and income disparities. Journal of Economic Theory, 20, 340-359.

Gale, D. (1973). Pure exchange equilibrium of dynamic economic models. Journal of Economic Theory, $6,12-36$.

Haupt, A., Krieger, T., \& Lange, T. (2016). Competition for the international pool of talent. Journal of Population Economics, 29, 1113-1154.

Haussen, T., \& Uebelmesser, S. (2016). Student and graduate migration and its effect on the financing of higher education. Education Economics, 24, 573-591.

Hunt, J. (2006). Staunching emigration from East Germany: Age and the determinants of migration. Journal of the European Economic Association, 4, 1014-1037.

Justman, M., \& Thisse, J.-F. (2000). Local public funding of higher education when skilled labor is imperfectly mobile. International Tax and Public Finance, 7, 247-258.

Kemnitz, A. (2007). University funding reform competition, and teaching quality. Journal of Institutional and Theoretical Economics, 163, 356-378.

Lange, T. (2009). Public funding of higher education when students and skilled workers are mobile. FinanzArchiv/ Public Finance Analysis, 65, 178-199.

Lange, T. (2013). Return migration of foreign students and non-resident tuition fees. Journal of Population Economics, 26, 703-718.

Lowell, L., Bump, M., \& Martin, S. (2007). Foreign students coming to America: The impact of policy, procedures, and economic competition, Project Summary Report, ISIM Georgetown University.

Lu, Y., Zong, L., \& Schissel, B. (2009). To stay or return: Migration intentions of students from People's Republic of China in Saskatchewan, Canada. International Migration and Integration, 10, 283-310.

Mauro, P., \& Spilimbergo, A. (1999). How do the skilled and the unskilled respond to regional shocks? The case of Spain. IMF Staff Papers, 46, 1-17.

Mechtenberg, L., \& Strausz, R. (2008). The Bologna process: how student mobility affects multi-cultural skills and educational quality. International Tax and Public Finance, 15, 109-130.

OECD (2019). Education at a Glance 2019, OECD, Paris.

Rosenzweig, M. (2006). Higher education and international migration in Asia: Brain circulation. Paper prepared for the Regional Bank Conference on Development Economics in Beijing: Higher Education and Development, January 2007.

Shaked, A., \& Sutton, J. (1982). Relaxing price competition through product differentiation. The Review of Economic Studies, 49, 3-13.

Tremblay, K. (2005). Academic mobility and immigration. Journal of Studies in International Education, 9, 196-228. 
Van Bouwel, L., \& Veugelers, R. (2014). Are foreign top Ph.D. students more likely to stay in the USA? Some evidence from European economists. In M. Gérard \& S. Uebelmesser (Eds.), From mobility of students to mobility of the highly skilled: Implications for fiscal and economic policy (pp. 57-81). CESifo Seminar Series. Cambridge: MIT Press.

Publisher's Note Springer Nature remains neutral with regard to jurisdictional claims in published maps and institutional affiliations. 